\title{
Large-scale analysis of structural brain asymmetries in schizophrenia via the ENIGMA consortium
}

Dick Schijven ${ }^{1}$, Merel C. Postema ${ }^{1,2}$, Masaki Fukunaga ${ }^{3}$, Junya Matsumoto ${ }^{4}$, Kenichiro Miura $^{4}$, Sonja M.C. de Zwarte ${ }^{5}$, Neeltje E.M. van Haren ${ }^{5,6}$, Wiepke Cahn ${ }^{5}$, Hilleke E. Hulshoff Pol $^{5}$, René S. Kahn ${ }^{5,7,8}$, Rosa Ayesa-Arriola ${ }^{9,10,11}$, Víctor Ortiz-García de la Foz ${ }^{10,12}$, Diana Tordesillas-Gutierrez ${ }^{9,10,13}$, Javier Vázquez-Bourgon ${ }^{9,10}$, Benedicto CrespoFacorro $^{10,14}$, Dag Alnæs ${ }^{15,16,17}$, Andreas Dahl ${ }^{16}$, Lars T. Westlye ${ }^{15,16,18,19}$ Ingrid Agartz $^{15,20,21}$, Ole A. Andreassen ${ }^{15,18}$, Erik G. Jönsson ${ }^{15,21}$, Peter Kochunov ${ }^{22}$, Jason M.

Bruggemann $^{23,24,25,26}$, Stanley V. Catts ${ }^{27}$, Patricia T. Michie ${ }^{28}$, Bryan J. Mowry ${ }^{29,30}$, Yann Quidé $^{23,24}$, Paul E. Rasser ${ }^{31,32,33}$, Ulrich Schall ${ }^{34}$, Rodney J. Scott ${ }^{35}$, Vaughan J. Carr ${ }^{23,24}$, Melissa J. Green ${ }^{23,24}$, Frans A. Henskens ${ }^{36,37}$, Carmel M. Loughland ${ }^{36,38}$, Christos Pantelis ${ }^{39}$, Cynthia Shannon Weickert ${ }^{23,24,40}$, Thomas W. Weickert ${ }^{23,24,40}$, Lieuwe de Haan ${ }^{41,42}$, Katharina Brosch $^{43,44}$, Julia-Katharina Pfarr ${ }^{43,44}$, Kai G. Ringwald ${ }^{43,44}$, Frederike Stein ${ }^{43,44}$, Andreas Jansen $^{43,44,45}$, Tilo T.J. Kircher ${ }^{43,44}$, Igor Nenadić ${ }^{43,44}$, Bernd Krämer ${ }^{46}$, Oliver Gruber ${ }^{46}$, Theodore D. Satterthwaite ${ }^{47,48,49}$, Juan Bustillo ${ }^{50}$, Daniel H. Mathalon ${ }^{51,52}$, Adrian Preda ${ }^{53}$, Vince D. Calhoun ${ }^{54,55}$, Judith M. Ford ${ }^{56}$, Steven G. Potkin ${ }^{53,57}$, Jingxu Chen ${ }^{58}$, Yunlong $\operatorname{Tan}^{58}$, Zhiren Wang ${ }^{58}$, Hong Xiang ${ }^{59}$, Fengmei Fan $^{58}$, Stefan Ehrlich ${ }^{60,61}$, Paola FuentesClaramonte $^{62,63}$, Maria Angeles Garcia-Leon ${ }^{62,63}$, Amalia Guerrero-Pedraza ${ }^{62,64}$, Raymond Salvador $^{62,63}$, Salvador Sarró ${ }^{62,63}$, Edith Pomarol-Clotet ${ }^{62,63}$, Valentina Ciullo ${ }^{65}$, Fabrizio Piras $^{66}$, Daniela Vecchio ${ }^{65}$, Nerisa Banaj ${ }^{65}$, Gianfranco Spalletta ${ }^{66}$, Stijn Michielse ${ }^{67}$, Therese van Amelsvoort ${ }^{67}$, Erin W. Dickie ${ }^{68,69}$, Aristotle N. Voineskos ${ }^{68,69}$, Kang Sim ${ }^{70,71}$, Simone Ciufolini $^{72}$, Paola Dazzan ${ }^{73}$, Robin M. Murray ${ }^{72}$, Woo-Sung Kim ${ }^{74,75}$, Young-Chul Chung $^{74,75}$, Christina Andreou ${ }^{76,77}$, André Schmidt ${ }^{76}$, Stefan Borgwardt ${ }^{76,77}$, Andrew M. McIntosh $^{78}$, Heather C. Whalley ${ }^{78}$, Stephen M. Lawrie ${ }^{78,79}$, Stefan du Plessis ${ }^{80}$, Hilmar K. Luckhoff $^{80}$, Freda Scheffler ${ }^{80}$, Robin Emsley ${ }^{80}$, Dominik Grotegerd ${ }^{81}$, Rebekka Lencer ${ }^{77,81}$, Udo Dannlowski $^{81}$, Jesse T. Edmond ${ }^{54}$, Kelly Rootes-Murdy ${ }^{54}$, Julia M. Stephen ${ }^{82}$, Andrew R. Mayer ${ }^{82}$, Linda A. Antonucci ${ }^{83}$, Leonardo Fazio ${ }^{84}$, Giulio Pergola ${ }^{84}$, Alessandro Bertolino $^{84,85}$, Covadonga M. Díaz-Caneja ${ }^{86,87,88}$, Joost Janssen ${ }^{86,87,88}$, Noemi G. Lois ${ }^{86,88}$, Celso Arango ${ }^{86,87,88,89}$, Alexander S. Tomyshev ${ }^{90}$, Irina Lebedeva ${ }^{90}$, Simon Cervenka ${ }^{21,91}$, Carl M. Sellgren ${ }^{21,92}$, Foivos Georgiadis ${ }^{93}$, Matthias Kirschner ${ }^{93,94}$, Stefan Kaiser ${ }^{93,95}$, Tomas Hajek $^{96,97}$, Antonin Skoch ${ }^{96,98}$, Filip Spaniel ${ }^{96}$, Minah Kim ${ }^{99,100}$, Yoo Bin Kwak ${ }^{101}$, Sanghoon $\mathrm{Oh}^{100}$, Jun Soo Kwon ${ }^{99,100}$, Anthony James ${ }^{102}$, Christian Knöchel ${ }^{103}$, Michael Stäblein ${ }^{103}$, Viola Oertel ${ }^{103}$, Anne Uhlmann ${ }^{104,105}$, Fleur M. Howells ${ }^{104,106}$, Dan J. Stein ${ }^{104,106,107}$, Henk S. Temmingh $^{104}$, Ana M. Diaz-Zuluaga ${ }^{108}$, Julian A. Pineda-Zapata ${ }^{108}$, Carlos LópezJaramillo $^{108}$, Stephanie Homan ${ }^{93,109}$, Ellen Ji ${ }^{93}$, Werner Surbeck ${ }^{93}$, Philipp Homan ${ }^{93,110,111,112}$, Simon E. Fisher ${ }^{1,113}$, Barbara Franke ${ }^{113,114,115}$, David C. Glahn ${ }^{116,117}$, Ruben C. Gur ${ }^{47,48,118,119}$, Ryota Hashimoto $^{4}$, Neda Jahanshad ${ }^{120}$, Eileen Luders ${ }^{121,122,123}$, Sarah E. Medland ${ }^{124}$, Paul M. Thompson ${ }^{120}$, Jessica A. Turner ${ }^{54,55}$, Theo G.M. van $\operatorname{Erp}^{125,126}$, Clyde Francks ${ }^{1,113, *}$ NOTE: This preprint reports new research that has not been certified by peer review and should not be used to guide clinical practice. 
medRxiv preprint doi: https://doi.org/10.1101/2022.03.01.22271652; this version posted March 2, 2022. The copyright holder for this preprint

(which was not certified by peer review) is the author/funder, who has granted medRxiv a license to display the preprint in perpetuity.

It is made available under a CC-BY-NC 4.0 International license.

1 Language \& Genetics Department, Max Planck Institute for Psycholinguistics, Nijmegen, The Netherlands

2 Alzheimer Center Amsterdam, Department of Neurology, Amsterdam Neuroscience, Amsterdam UMC, Vrije Universiteit Amsterdam, Amsterdam, The Netherlands

3 Division of Cerebral Integration, National Institute for Physiological Sciences, Okazaki, Aichi, Japan

4 Department of Pathology of Mental Diseases, National Institute of Mental Health, National Center of Neurology and Psychiatry, Tokyo, Japan

5 Department of Psychiatry, University Medical Center Utrecht Brain Center, University Medical Center Utrecht, Utrecht University, Utrecht, The Netherlands

6 Department of Child and Adolescent Psychiatry/Psychology, Erasmus University Medical Center-Sophia Children's Hospital, Rotterdam, The Netherlands

7 Department of Psychiatry, Icahn School of Medicine at Mount Sinai, New York, NY, USA

8 The Mental Illness Research, Education and Clinical Centers (MIRECC), James J. Peters VA Medical Center, Bronx, New York, NY, USA

9 Department of Psychiatry, University Hospital Marqués de Valdecilla, Instituto de Investigación Marqués de Valdecilla (IDIVAL), Santander, Spain

10 Centro de Investigación Biomédica en Red de Salud Mental (CIBERSAM), Instituto de Salud Carlos III, Madrid, Spain

11 Department of Medicine and Psychiatry, School of Medicine, University of Cantabria, Santander, Spain 12 Department of Psychiatry, Marqués de Valdecilla University Hospital, IDIVAL, School of Medicine, University of Cantabria, Santander, Spain

13 Department of Radiology, University Hospital Marqués de Valdecilla, Instituto de Investigación Marqués de Valdecilla (IDIVAL), Santander, Spain

14 Department of Psychiatry, School of Medicine, University Hospital Virgen del Rocío - IBiS, Sevilla, Spain 15 Norwegian Centre for Mental Disorders Research (NORMENT), Institute of Clinical Medicine, University of Oslo, Oslo, Norway

16 Department of Psychology, University of Oslo, Oslo, Norway

17 Bjørknes College, Oslo, Norway

18 Division of Mental Health and Addiction, Oslo University Hospital, Oslo, Norway

19 KG Jebsen Center for Neurodevelopmental Disorders, University of Oslo, Oslo, Norway

20 Department of Psychiatric Research, Diakonhjemmet Hospital, Oslo, Norway

21 Centre for Psychiatry Research, Department of Clinical Neuroscience, Karolinska Institutet \& Stockholm Health Care Services, Region Stockholm, Stockholm, Sweden

22 Department of Psychiatry, University of Maryland School of Medicine, Baltimore, MD, USA

23 School of Psychiatry, University of New South Wales (UNSW), Sydney, NSW, Australia

24 Neuroscience Research Australia, Randwick, NSW, Australia

25 Edith Collins Centre (Translational Research in Alcohol Drugs \& Toxicology), Sydney Local Health District, Sydney, NSW, Australia

26 Specialty of Addiction Medicine, Central Clinical School, Faculty of Medicine and Health, University of Sydney, Sydney, NSW, Australia

27 School of Medicine, University of Queensland, Herston, QLD, Australia

28 School of Psychological Sciences, University of Newcastle, Callaghan, NSW, Australia

29 Queensland Brain Institute, The University of Queensland, Brisbane, QLD, Australia

30 Queensland Centre for Mental Health Research, The University of Queensland, Brisbane, QLD, Australia

31 Centre for Brain and Mental Health Research, University of Newcastle, Callaghan, NSW, Australia

32 Priority Research Centre for Stroke and Brain Injury, University of Newcastle, Callaghan, NSW, Australia

33 Hunter Medical Research Institute (HMRI), New Lambton Heights, NSW, Australia

34 Centre for Brain and Mental Health Research, The University of Newcastle, Waratah, NSW, Australia

35 School of Biomedical Science and Pharmacy, Faculty of Health and Medicine, University of Newcastle,

Callaghan, NSW, Australia

36 School of Medicine and Public Health, University of Newcastle, Callaghan, NSW, Australia

37 PRC for Health Behaviour, Hunter Medical Research Institute, New Lambton Heights, NSW, Australia

38 Hunter New England Mental Health Service, Newcastle, NSW, Australia 
medRxiv preprint doi: https://doi.org/10.1101/2022.03.01.22271652; this version posted March 2, 2022. The copyright holder for this preprint

(which was not certified by peer review) is the author/funder, who has granted medRxiv a license to display the preprint in perpetuity.

It is made available under a CC-BY-NC 4.0 International license.

39 Melbourne Neuropsychiatry Centre, Department of Psychiatry, University of Melbourne, Carlton South, VIC, Australia

40 Department of Neuroscience and Physiology, Upstate Medical University, Syracuse, NY, USA

41 Early Psychosis Department, Department of Psychiatry, Amsterdam UMC (location AMC), Amsterdam, The Netherlands

42 Arkin Institute for Mental Health, Amsterdam, The Netherlands

43 Department of Psychiatry and Psychotherapy, Philipps-Universität Marburg, Marburg, Germany

44 Center for Mind, Brain and Behavior (CMBB), Marburg, Germany

45 Core-Facility Brainimaging, Faculty of Medicine, Philipps-Universität Marburg, Marburg, Germany

46 Section for Experimental Psychopathology and Neuroimaging, Department of General Psychiatry,

Heidelberg University, Heidelberg, Germany

47 Department of Psychiatry, Perelman School of Medicine, University of Pennsylvania, Philadelphia, PA, USA

48 Lifespan Brain Institute, University of Pennsylvania \& Children's Hospital of Philadelphia, Philadelphia, PA, USA

49 Center for Biomedical Image Computing and Analytics, Perelman School of Medicine, University of Pennsylvania, Philadelphia, PA, USA

50 Department of Psychiatry and Neuroscience, University of New Mexico, Albuquerque, NM, USA

51 Department of Psychiatry and Behavioral Sciences and Weill Institute for Neurosciences, University of California, San Francisco, CA, USA

52 Mental Health Service, Veterans Affairs San Francisco Healthcare System, San Francisco, CA, USA

53 Department of Psychiatry and Human Behavior, University of California Irvine, Irvine, CA, USA

54 Psychology Department and Neuroscience Institute, Georgia State University, Atlanta, GA, USA

55 Tri-Institutional Center for Translational Research in Neuroimaging and Data Science (TReNDS), Georgia

State University, Georgia Institute of Technology and Emory University, Atlanta, GA, USA

56 San Francisco VA Medical Center, University of California, San Francisco, CA, USA

57 Long Beach VA Health Care System, Long Beach, CA, USA

58 Beijing Huilongguan Hospital, Peking University Huilongguan Clinical Medical School, Beijing, P. R. China

59 Chongqing University Three Gorges Hospital, Chongqing, P.R. China

60 Division of Psychological and Social Medicine and Developmental Neurosciences, Translational

Developmental Neuroscience Section, Technische Universität Dresden, University Hospital C.G. Carus,

Dresden, Germany

61 Department of Child and Adolescent Psychiatry, Eating Disorder Treatment and Research Center,

Technische Universität Dresden, Faculty of Medicine, University Hospital C. G. Carus, Dresden, Germany

62 FIDMAG Germanes Hospitalàries Research Foundation, Barcelona, Spain

63 Mental Health Research Networking Center (CIBERSAM), Madrid, Spain

64 Benito Menni Complex Assistencial en Salut Mental, Barcelona, Spain

65 Department of Clinical and Behavioral Neurology, Laboratory of Neuropsychiatry, IRCCS Santa Lucia

Foundation, Rome, Italy

66 Laboratory of Neuropsychiatry, IRCCS Santa Lucia Foundation, Rome, Italy

67 Department of Psychiatry and Neuropsychology, School for Mental Health and Neuroscience, Maastricht

University Medical Centre, Maastricht University, Maastricht, The Netherlands

68 Campbell Family Mental Health Institute, Centre for Addiction and Mental Health, Toronto, Canada

69 Department of Psychiatry, University of Toronto, Toronto, Canada

70 West Region, Institute of Mental Health, Singapore, Singapore

71 Yong Loo Lin School of Medicine, National University of Singapore, Singapore, Singapore

72 Department of Psychosis Studies, Institute of Psychiatry, Psychology and Neuroscience, King's College

London, London, United Kingdom

73 Department of Psychological Medicine, Institute of Psychiatry, Psychology and Neuroscience, King's

College London, London, United Kingdom

74 Department of Psychiatry, Jeonbuk National University Medical School, Jeonju, Republic of Korea

75 Research Institute of Clinical Medicine, Jeonbuk National University-Biomedical Research Institute,

Jeonbuk National University Hospital, Jeonju, Republic of Korea 
medRxiv preprint doi: https://doi.org/10.1101/2022.03.01.22271652; this version posted March 2, 2022. The copyright holder for this preprint

(which was not certified by peer review) is the author/funder, who has granted medRxiv a license to display the preprint in perpetuity.

It is made available under a CC-BY-NC 4.0 International license.

76 Department of Psychiatry, University Psychiatric Clinics (UPK), University of Basel, Basel, Switzerland 77 Department of Psychiatry and Psychotherapy, University of Lübeck, Lübeck, Germany

78 Division of Psychiatry, Centre for Clinical Brain Sciences, University of Edinburgh, Edinburgh, United Kingdom

79 Patrick Wild Centre, Centre for Clinical Brain Sciences, University of Edinburgh, Edinburgh, United

Kingdom

80 Department of Psychiatry, Faculty of Medicine and Health Sciences, Stellenbosch University, Stellenbosch, South Africa

81 Institute for Translational Psychiatry, Westfälische Wilhelms-Universität Münster, Münster, Germany

82 The Mind Research Network, Albuquerque, NM, USA

83 Department of Education, Psychology, Communication, University of Bari Aldo Moro, Bari, Italy

84 Department of Basic Medical Science, Neuroscience and Sense Organs, University of Bari Aldo Moro, Bari, Italy

85 Psychiatry Unit, Bari University Hospital, Bari, Italy

86 Department of Child and Adolescent Psychiatry, Institute of Psychiatry and Mental Health, Hospital General Universitario Gregorio Marañón, Madrid, Spain

87 Ciber del Área de Salud Mental (CIBERSAM), Madrid, Spain

88 Instituto de Investigación Sanitaria Gregorio Marañón (IiSGM), Madrid, Spain

89 School of Medicine, Universidad Complutense, Madrid, Spain

90 Laboratory of Neuroimaging and Multimodal Analysis, Mental Health Research Center, Moscow, Russian

Federation

91 Department of Neuroscience, Psychiatry, Uppsala University, Uppsala, Sweden

92 Department of Physiology and Pharmacology, Karolinska Institutet, Stockholm, Sweden

93 Department of Psychiatry, Psychotherapy and Psychosomatics, Psychiatric University Hospital Zurich

(PUK), Zurich, Switzerland

94 Montreal Neurological Institute, McGill University, Montreal, Canada

95 Department of Psychiatry, Division of Adult Psychiatry, Geneva University Hospitals, Geneva, Switzerland 96 National Institute of Mental Health, Klecany, Czech Republic

97 Department of Psychiatry, Dalhousie University, Halifax, Canada

98 MR Unit, Department of Diagnostic and Interventional Radiology, Institute for Clinical and Experimental

Medicine, Prague, Czech Republic

99 Department of Neuropsychiatry, Seoul National University Hospital, Seoul, Republic of Korea

100 Department of Psychiatry, Seoul National University College of Medicine, Seoul, Republic of Korea

101 Department of Brain and Cognitive Sciences, Seoul National University College of Natural Sciences, Seoul, Republic of Korea

102 Department of Psychiatry, University of Oxford, Oxford, United Kingdom

103 Department of Psychiatry, Psychosomatic Medicine and Psychotherapy, University Hospital Frankfurt,

Frankfurt am Main, Germany

104 Department of Psychiatry and Mental Health, Faculty of Health Sciences, University of Cape Town, Cape

Town, South Africa

105 Department of Child and Adolescent Psychiatry, Technische Universität Dresden, Dresden, Germany

106 Neuroscience Institute, University of Cape Town, Cape Town, South Africa

107 SA MRC Unit on Risk \& Resilience in Mental Disorders, University of Cape Town, Cape Town, South

Africa

108 Research Group in Psychiatry (GIPSI), Department of Psychiatry, Faculty of Medicine, Universidad de

Antioquia, Medellín, Colombia

109 Experimental Psychopathology and Psychotherapy, Department of Psychology, University of Zurich,

Switzerland

110 Center for Psychiatric Neuroscience, Feinstein Institute for Medical Research, Manhasset, NY, USA

111 Division of Psychiatry Research, Zucker Hillside Hospital, Northwell Health, New York, NY, USA

112 Department of Psychiatry, Zucker School of Medicine at Northwell/Hofstra, Hempstead, NY, USA

113 Donders Institute for Brain, Cognition and Behaviour, Radboud University, Nijmegen, The Netherlands 
medRxiv preprint doi: https://doi.org/10.1101/2022.03.01.22271652; this version posted March 2, 2022. The copyright holder for this preprint

(which was not certified by peer review) is the author/funder, who has granted medRxiv a license to display the preprint in perpetuity.

It is made available under a CC-BY-NC 4.0 International license.

114 Department of Human Genetics, Radboud University Medical Center, Nijmegen, The Netherlands

115 Department of Psychiatry, Radboud University Medical Center, Nijmegen, The Netherlands

116 Department of Psychiatry, Boston Children's Hospital and Harvard Medical School, Boston, MA, USA

117 Olin Neuropsychiatry Research Center, Institute of Living, Hartford, CT, USA

118 Department of Radiology, Perelman School of Medicine, Philadelphia, PA, USA

119 Department of Neurology, Perelman School of Medicine, Philadelphia, PA, USA

120 Imaging Genetics Center, Mark \& Mary Stevens Neuroimaging \& Informatics Institute, Keck School of Medicine, University of Southern California, Los Angeles, CA, USA

121 School of Psychology, University of Auckland, Auckland, New Zealand

122 Department of Women's and Children's Health, Uppsala University, Uppsala, Sweden

123 Laboratory of Neuro Imaging, School of Medicine, University of Southern California, Los Angeles, USA

124 Psychiatric Genetics, QIMR Berghofer Medical Research Institute, Brisbane, QLD, Australia

125 Clinical Translational Neuroscience Laboratory, Department of Psychiatry and Human Behavior, University of California Irvine, Irvine, CA, USA

126 Center for the Neurobiology of Learning and Memory, University of California Irvine, Irvine, CA, USA

* Corresponding author: Clyde Francks, D.Phil., Wundtlaan 1, 6525 XD Nijmegen, The Netherlands; e-mail: Clyde.Francks@mpi.nl; telephone: +31 (0)24-3521929

Running Title: Structural brain asymmetries in schizophrenia

Keywords: schizophrenia, laterality, asymmetry, structural magnetic resonance imaging, cortical, subcortical 
medRxiv preprint doi: https://doi.org/10.1101/2022.03.01.22271652; this version posted March 2, 2022. The copyright holder for this preprint

(which was not certified by peer review) is the author/funder, who has granted medRxiv a license to display the preprint in perpetuity.

It is made available under a CC-BY-NC 4.0 International license.

\begin{abstract}
BACKGROUND: Left-right asymmetry is an important organizing feature of the healthy brain that may be altered in schizophrenia, but most studies have used relatively small samples and heterogeneous approaches, resulting in equivocal findings. We carried out the largest case-control study of structural brain asymmetries in schizophrenia $(\mathrm{N}=11,095)$, using a single image analysis protocol.
\end{abstract}

METHODS: We included T1-weighted data from 46 datasets (5,080 affected individuals and 6,015 controls) from the ENIGMA Consortium. Asymmetry indexes were calculated for global and regional cortical thickness, surface area, and subcortical volume measures. Differences of asymmetry were calculated between affected individuals and controls per dataset, and effect sizes were meta-analyzed across datasets. Analyses were also performed with respect to the use of antipsychotic medication and other clinical variables, as well as age and sex. Case-control differences in a multivariate context were assessed in a subset of the data $(\mathrm{N}=2,029)$.

RESULTS: Small average differences between cases and controls were observed for asymmetries in cortical thickness, specifically of the rostral anterior cingulate $\left(d=-0.08, p_{\mathrm{FDR}}=0.047\right)$ and the middle temporal gyrus $\left(d=-0.07, p_{\mathrm{FDR}}=0.048\right)$, both driven primarily by thinner cortices in the left hemisphere in schizophrenia. These asymmetries were not significantly associated with the use of antipsychotic medication or other clinical variables. Older individuals with schizophrenia showed a stronger average leftward asymmetry of pallidum volume than older controls $\left(d=0.08, p_{\mathrm{FDR}}=9.0 \mathrm{x}\right.$ $10^{-3}$ ). The multivariate analysis revealed that $7 \%$ of the variance across all structural asymmetries was explained by case-control status $\left(F=1.87, p=1.25 \times 10^{-5}\right)$.

CONCLUSIONS: Altered trajectories of asymmetrical brain development and/or lifespan asymmetry may contribute to schizophrenia pathophysiology. Small case-control differences of brain macrostructural asymmetry may manifest due to more substantial differences at the molecular, cytoarchitectonic or circuit levels, with functional relevance for lateralized cognitive processes. 
medRxiv preprint doi: https://doi.org/10.1101/2022.03.01.22271652; this version posted March 2, 2022. The copyright holder for this preprint

(which was not certified by peer review) is the author/funder, who has granted medRxiv a license to display the preprint in perpetuity.

It is made available under a CC-BY-NC 4.0 International license .

\section{Introduction}

Schizophrenia is a serious mental illness characterized by various combinations of symptoms that may include delusions, hallucinations, disorganized speech, affective flattening, avolition, and executive function deficits (1). Left-right asymmetry is an important feature of human brain organization for diverse cognitive functions - for example, roughly $90 \%$ of people present with a left-hemisphere dominance for language and right-handedness (2-5). A possible role of altered structural and functional brain asymmetry in schizophrenia has been studied for several decades (6-10). Theoretical work has especially focused on disrupted laterality for language in relation to disorganized speech and auditory hallucinations (11-13). Individuals with schizophrenia have been reported to show a decreased left-lateralized language dominance $(14,15)$, as well as an absence or even reversal of structural asymmetries of language-related regions around the Sylvian fissure (which divides the temporal lobe from the frontal and parietal lobes) $(13,16-18)$. Furthermore, the rate of non-righthandedness in schizophrenia is elevated compared to the general population $(13,19-23)$. Interestingly, some genomic loci that influence aspects of structural brain asymmetry or hand preference overlap with those associated with schizophrenia (24-27). Thus, there might be an etiological link between altered brain asymmetry and schizophrenia.

However, alterations in structural brain asymmetry in schizophrenia have so far only been reported in studies with relatively small samples $(13,16-18,28-34)$; to our knowledge, the largest case-control sample consisted of 167 affected individuals and 159 controls (31). Many of the existing findings are inconsistent and/or remain unreplicated, which is possibly due to the low statistical power which limits the sensitivity to detect true effects, and also increases the risk of overestimating effect sizes $(35,36)$. The reproducibility of findings may be further affected by the heterogeneity of clinical and demographic characteristics across studies. Moreover, varying approaches to process and analyze magnetic resonance imaging (MRI) data limit the possibility to reproduce results and/or to perform meta-analyses. For example, in studies targeting specific regions of interest, regions have been inconsistently defined, while studies that involved cortex-wide mapping used different image analysis protocols. Studies of subcortical volumetric asymmetries in schizophrenia have generally suffered from similar issues (37-39), with the notable exception of a study in 884 affected individuals and 1,680 controls that used a single image analysis pipeline (40). This study found an increased leftward asymmetry of the pallidum in schizophrenia (driven by a larger pallidum volume in the left hemisphere) compared to controls, which was also detectable in adolescents with subclinical psychotic experiences $(40,41)$.

The Enhancing Neuro Imaging Genetics through Meta-Analysis (ENIGMA, http://enigma.ini.usc.edu) consortium aims to perform large-scale analyses by combining imaging data from research groups 
medRxiv preprint doi: https://doi.org/10.1101/2022.03.01.22271652; this version posted March 2, 2022. The copyright holder for this preprint

(which was not certified by peer review) is the author/funder, who has granted medRxiv a license to display the preprint in perpetuity.

It is made available under a CC-BY-NC 4.0 International license .

across the world, processed with standardized protocols $(42,43)$. Previously, this consortium reported large-scale cortical thinning, smaller surface area, and altered subcortical volume in individuals with schizophrenia compared to controls $(44,45)$. However, asymmetry was not measured in these previous ENIGMA studies, and no tests were performed to assess whether case-control effects were different in the two hemispheres. The ENIGMA consortium has investigated structural brain asymmetries in other disorders (46): major depressive disorder (MDD) (47), autism spectrum disorder (ASD) (48), obsessive compulsive disorder (OCD) (49), and attention deficit/hyperactivity disorder (ADHD) (50), but not schizophrenia to date. Case-control group-level effects were small for all of these disorders, with ASD showing the most widespread asymmetry differences - mostly involving regional cortical thickness measures - with a maximum Cohen's $d$ of 0.13 (48). Similar effect sizes may be anticipated for schizophrenia. Therefore, a large sample size is likely required to detect and accurately measure any effects. Although small group-average differences of brain macro-anatomy are unlikely to have clinical uses by themselves, they may help to identify brain regions and networks that have clinically relevant disruptions at other neurobiological levels - for example molecular or cytoarchitectonic - which can be investigated in future studies. Of note, the ENIGMA consortium has recently reported on asymmetry alterations with respect to subcortical shape $(2,833$ individuals with schizophrenia versus 3,929 controls), based on an automated approach quantifying local concave versus convex surface curvature (51), but this study did not address subcortical volume asymmetries, and omitted the cerebral cortex .

Therefore, we designed the current study focusing on cortical and subcortical structural asymmetries in schizophrenia using the largest sample to date, containing 5,080 affected individuals and 6,015 controls from 46 separate datasets. The datasets were collected originally as distinct studies over approximately 25 years, using different recruitment schemes, MRI scanning equipment and parameters. Importantly, for the current study, all primary MRI data were processed through a single pipeline for cortical atlas-based segmentation/subcortical parcellation and quality control. Casecontrol differences were tested separately for each regional asymmetry index (AI) within each dataset, and effects were then combined across datasets using meta-analysis methodology. This approach was taken due to restrictions on sharing individual-level data for many of the primary datasets. We also explored possible associations of structural brain asymmetries with medication use and other disorderspecific measures: age at onset, duration of illness, as well as total, positive, and negative symptom scores. For 14 datasets, for which individual-level data were available, we tested for a multivariate association of case-control status simultaneously with regional AIs across the brain. Together, these analyses aimed to provide novel insights into the extent and mapping of structural brain asymmetry alterations in schizophrenia, and how they relate to key clinical variables. 


\section{Methods and materials}

\section{Datasets}

Structural MRI data were derived from 46 separate datasets (45 case-control and one case-only) via researcher participation in the ENIGMA schizophrenia working group, totaling 11,095 individuals. Of these, 5,080 were affected with schizophrenia and 6,015 were unaffected controls (Table 1, Table S1A). The datasets came from various countries around the world (Figure 1). Data collection was performed after written informed consent and was approved by local institutional review boards. Sample size-weighted mean age across datasets was 33.3 (range 16.2-44.0) years for individuals with schizophrenia and 33.0 (11.8-43.6) years for controls. Affected individuals and controls were 67\% and 52\% male, respectively. Diagnostic interviews were conducted by registered clinical research staff using different diagnostic criteria (either the Diagnostic and Statistical Manual of Mental Disorders [DSM]-III, DSM-IV, DSM-5 or International Classification of Diseases [ICD]-10), and hand preference was obtained through assessment scales (mainly the Edinburgh Handedness Inventory and Annett Handedness Scale) or self-report (Table S2). No controls had present or past indications of schizophrenia.

\section{Image acquisition, processing and quality control}

T1-weighted structural brain MRI scans were acquired at each study site. Site-specific scanner information, field strengths ( $1 \mathrm{~T}, 1.5 \mathrm{~T}$, and $3 \mathrm{~T})$, and image acquisition parameters are provided in Table S2. For data from all sites, image processing and segmentation were performed using FreeSurfer (see Table S2 for software versions) (52). For each individual, using the 'recon-all' pipeline, cerebral cortical thickness and surface area measures were derived for 34 bilaterally paired Desikan-Killiany (DK) atlas regions, as well as whole hemisphere-level average cortical thickness and surface area measures (53). Volumes for 8 bilaterally paired regions from a neuroanatomical atlas of brain subcortical structures (54) were derived using the 'aseg' segmentation command in FreeSurfer. A standardized ENIGMA quality control procedure was applied at each participating site (described in full here: http://enigma.ini.usc.edu/protocols/imaging-protocols/). Briefly, this included outlier detection in the derived cortical and subcortical measures and visual inspection of segmentations projected onto the T1-weighted image of each individual. For cortical measures, predefined guidelines for visual inspection were followed. Measurements from regions with poor segmentation were excluded, as well as individuals whose data failed overall quality checks. Data sharing limitations did not allow the central analysis group to have access to individual-level data for the majority of participating study sites. For further processing and analyses of the data, a script running in $\mathrm{R}$ software (R Foundation for Statistical Computing, Vienna, Austria, www.R-project.org) (55) was prepared and distributed among participating sites, to ensure coordinated collection of descriptive and summary statistics for subsequent meta-analysis by the central analysis team. 
medRxiv preprint doi: https://doi.org/10.1101/2022.03.01.22271652; this version posted March 2, 2022. The copyright holder for this preprint

(which was not certified by peer review) is the author/funder, who has granted medRxiv a license to display the preprint in perpetuity.

It is made available under a CC-BY-NC 4.0 International license .

\section{Asymmetry index calculation}

For each bilaterally paired brain regional measure, we used the left $(L)$ and right $(R)$ hemispheric measurements to calculate an asymmetry index $(\mathrm{AI}),=\frac{L-R}{(L+R) / 2}$, where the denominator corrects for automatic scaling of the index with the magnitude of the bilateral measure. This formula for AI calculation has been widely used $(2,49,56-58)$. A negative value of the AI reflects a larger right hemispheric measurement $(R>L)$, and a positive value a larger left hemispheric measurement $(L>$ $R$ ). Distributions of AIs were plotted using histograms to allow for visual inspection. Left or right measurements equal to 0 were set to missing, as these most likely reflected data entry errors. Furthermore, when a left or right measurement was missing, the corresponding measurement in the opposite hemisphere was also set to missing. The standardized pipeline from raw image data through FreeSurfer does not introduce left-right flipping errors, but to ensure that such errors were not introduced during processing of raw imaging data by non-standard processes (e.g. during the conversion of DICOM to NIFTI files with bespoke scripts), we compared mean regional asymmetries for all datasets against grand sample-size adjusted means. If we noticed a large proportion of reversed average asymmetries for a dataset, we contacted the relevant site to re-check and correct their process (Table S3).

\section{Asymmetry differences between individuals with schizophrenia and unaffected controls}

Group differences were examined separately for each brain regional AI and each case-control dataset, using univariate linear regression implemented in R. Our primary analysis model included diagnosis (case-control status) as the main binary predictor, and sex and age as covariates (model 1 in Supplementary Note 1). For ten datasets where more than one scanner had been used (Table S2), we added $n-1$ binary dummy covariates (where $n$ is the number of scanners in a given dataset), to statistically control for scanner effects. Sex was not included as a covariate for the RSCZ dataset, as this dataset included only males. Collinearity between predictor variables was assessed using the Rpackage $u s d m$ (v1-1.18) (59), and high collinearity (variance inflation factor > 5) was not found for any dataset. Linear regression analysis for any structural AI was not performed if the total sample size of a given dataset was lower than ten plus the number of scanner covariates, or if one of the diagnostic groups had a sample size lower than five. For each brain regional AI and each case-control dataset, we extracted the $t$-statistic for the 'diagnosis' term to calculate its corresponding Cohen's $d$ effect size, standard error and $95 \%$ confidence interval, using

$d=\frac{t\left(n_{1}+n_{2}\right)}{\sqrt{n_{1} n_{2}} \sqrt{d f}}, s e_{d}=\sqrt{\left(\frac{n_{1}+n_{2}-1}{n_{1}+n_{2}-3}\right)\left[\left(\frac{4}{n_{1}+n_{2}}\right)\left(1+\frac{d^{2}}{8}\right)\right]}$, and 95\% CI $=\left[d-1.96 * s e_{d}, d+1.96 * s e_{d}\right](60)$. In these equations, $d$ is the Cohen's $d$ effect size, $t$ is the $t$-statistic, $s e$ is the standard error, $n_{1}$ is the 
medRxiv preprint doi: https://doi.org/10.1101/2022.03.01.22271652; this version posted March 2, 2022. The copyright holder for this preprint

(which was not certified by peer review) is the author/funder, who has granted medRxiv a license to display the preprint in perpetuity.

It is made available under a CC-BY-NC 4.0 International license .

number of unaffected controls, $n_{2}$ is the number of individuals with schizophrenia, and $d f$ the degrees of freedom in the linear model.

\section{Random-effects meta-analysis}

For each brain regional AI (Figure S1-S3), effect sizes for 'diagnosis' from each case-control dataset were meta-analyzed in a random-effects model fitted with a restricted maximum likelihood (REML) estimator, using the function 'rma' in the R package metafor (v3.0-2) (61). Meta-analyzed effect sizes were projected on 3D meshes of inflated cortical or subcortical models from Brainder (www.brainder.org/research/brain-for-blender/), using Matlab R2020a (version 9.8.0.1323502; MathWorks, Natick, MA, USA). We calculated false discovery rate (FDR) corrected p-values using the Benjamini-Hochberg method to account for multiple tests (62) (i.e., separately for testing 35 cortical thickness AIs, 35 cortical surface area AIs, and eight subcortical volume AIs). Effects with $p_{\mathrm{FDR}}<0.05$ were considered statistically significant. For AIs that showed significant group differences between cases and controls, the group differences for the corresponding left and right measurements separately were also assessed post hoc (again using linear modelling with diagnosis, age and sex as predictors), to help describe the asymmetry differences.

\section{Sensitivity analyses}

For any AI that showed a significant case-control group difference in the primary meta-analysis, we identified datasets within which the $95 \%$ CI of the diagnosis effect did not overlap with the $95 \%$ CI of the meta-analyzed effect - using the 'find.outliers' function in the R package dmetar (v0.0.9) (63) and then repeated the meta-analysis after excluding such outlier datasets. In addition, for any AI that showed a significant case-control group difference in the primary meta-analysis, we also applied models that included the same covariates as the primary analysis, but also included either handedness (right-handed vs. non-right-handed), intracranial volume (ICV), both handedness and ICV, or age ${ }^{2}$ (models 2-5 in Supplementary Note 1).

\section{Medication group differences}

For AIs that showed significant case-control group differences in the primary analysis, we explored associations with antipsychotic medication use at the time of scanning, through between-group comparisons of AIs of unmedicated individuals with schizophrenia, affected individuals taking only first-generation (typical) antipsychotics, affected individuals taking only second-generation (atypical) antipsychotics, and those taking both first- and second-generation antipsychotics. Sex and age were included as covariates (model 6 in Supplementary Note 1) and derived Cohen's $d$ effect sizes were again meta-analyzed across datasets in a random-effects model. Applying a minimum group size threshold of 5 within any given dataset, sufficient data on the presence/absence of antipsychotic 
medRxiv preprint doi: https://doi.org/10.1101/2022.03.01.22271652; this version posted March 2, 2022. The copyright holder for this preprint

(which was not certified by peer review) is the author/funder, who has granted medRxiv a license to display the preprint in perpetuity.

It is made available under a CC-BY-NC 4.0 International license .

medication use for at least one comparison were available for 31 of the datasets (Table S1B), and the sample sizes for each between-group comparison are in Table S9. We calculated FDR corrected pvalues to correct for all of the multiple subgroup comparisons and structural asymmetries tested.

\section{Correlations of asymmetries with clinical variables}

For AIs that showed significant case-control group differences in the primary analysis, we assessed relationships between these AIs and clinical variables within affected individuals only: age at onset, duration of illness, chlorpromazine equivalent medication dose (at the time of scanning), as well as positive, negative, and total symptom severity scores from the Positive and Negative Symptom Scale (PANSS) (64), or the Scale for the Assessment of Positive Symptoms (SAPS) (65) and Scale for the Assessment of Negative Symptoms (SANS) (66) (separately depending on data availability, see Table S1A). Partial correlations between brain AIs and these quantitative measures were estimated using the 'pcor.test' function in the R package ppcor (v1.1) (67). Age and sex were included as covariates (model 7 in Supplementary Note 1). The same minimum sample size requirement for dataset inclusion was applied as in the linear regression analyses (above). Correlation coefficients were meta-analyzed across datasets in a mixed-effects model including dataset as a random effect. We calculated FDR corrected p-values to control for all of the clinical variables and structural asymmetries tested. Sample sizes for each model are shown in Table S10.

\section{Secondary analysis of age- or sex-specific effects}

For all AIs in all case-control datasets we applied models which were the same as the primary analysis but additionally included either diagnosis-by-age or diagnosis-by-sex interaction terms. We then carried out meta-analyses of the interaction effect estimates across datasets to assess possible AI differences between affected individuals and controls that were relatively specific to either males or females, or differed with age (models 8-9 in Supplementary Note 1). In the same way as our primary analysis, we calculated FDR corrected p-values to account for multiple regional asymmetries tested.

\section{Multivariate analysis of case-control asymmetry differences}

To examine case-control group differences across all brain regional AIs simultaneously in one model, we conducted a multivariate analysis based on 14 datasets for which individual-level data were available to the central analysis team. For this analysis, we only retained individuals with complete data for all bilateral measures of cortical and subcortical structure, which were 935 individuals affected with schizophrenia and 1,095 unaffected controls (Table S1C). We separately adjusted the left and right measurements using ComBat harmonization (an empirical Bayesian method) to remove dataset effects (68), where each dataset (and each scanner within multi-scanner datasets) was treated as a distinct 'batch'. Diagnosis, age and sex were used as covariates when finding the data 
medRxiv preprint doi: https://doi.org/10.1101/2022.03.01.22271652; this version posted March 2, 2022. The copyright holder for this preprint

(which was not certified by peer review) is the author/funder, who has granted medRxiv a license to display the preprint in perpetuity.

It is made available under a CC-BY-NC 4.0 International license .

harmonization parameters in ComBat. After ComBat adjustment, one additional control individual was removed due to being assigned a negative corrected right hemisphere lateral ventricle volume (Figure S4). AIs for cortical and subcortical measures were then calculated using the same formula as above, and collinearity between AIs was assessed by calculating a correlation matrix. AIs did not show higher pairwise correlations than 0.5 (Figure S5-S6) A multivariate analysis of covariance (MANCOVA) using the 'manova' function in $\mathrm{R}$ was applied, testing all 76 regional structural brain AIs simultaneously against case-control status, with age and sex as covariates. We ran one million label-swapping permutations of case-control labels and calculated a permutation $p$-value by assessing the number of times the $F$-statistic of an analysis with permuted data was equal to or larger than the $F$ statistic of the analysis with real data, divided by the total number of permutations. When permuting case-control labels, we conserved case-control numbers within each dataset (and within scanner for multi-scanner datasets). To help interpret the MANCOVA results, we also derived univariate casecontrol association statistics for each separate structural AI from the multivariate association analysis output, using ANCOVA ('summary.aov' function in R).

\section{Results}

\section{Asymmetry differences between individuals with schizophrenia and unaffected controls}

In our primary analysis (model 1$)$, total hemispheric average cortical thickness $(d=-0.053, z=-1.92$, $p=0.055)$ and surface area $(d=0.027, z=1.23, p=0.22)$ did not significantly differ between affected individuals and controls. At a regional level (Figure 2, Table S4, Figure S1-S3), there was a small but significant case-control difference in cortical thickness asymmetry of the rostral anterior cingulate cortex $\left(d=-0.083, z=-3.21, p=1.3 \times 10^{-3}, p_{\mathrm{FDR}}=0.047\right.$, reversal from leftward average asymmetry in controls to rightward average asymmetry in cases), and also in cortical thickness asymmetry of the middle temporal gyrus $\left(d=-0.074, z=-2.99, p=2.8 \times 10^{-3}, p_{\mathrm{FDR}}=0.048\right.$, increased average rightward asymmetry in cases) (Figure 3, Figure S7-S8, Table S5). Post hoc analysis of unilateral effects showed that both of these regional asymmetry differences were driven primarily by thinner left than right cortex in individuals with schizophrenia compared to controls (Table 2, Table S6). The middle temporal cortex is a core language network region (69), and left-hemisphere thinning is compatible with disrupted leftward laterality of brain organization for language in schizophrenia $(10,11)$. Nominally significant regional case-control associations (i.e. which did not survive multiple testing correction), were found for the AIs of inferior parietal cortex thickness, cuneus surface area, parahippocampal gyrus surface area, and nucleus accumbens volume (Figure 3, Table S5). 
medRxiv preprint doi: https://doi.org/10.1101/2022.03.01.22271652; this version posted March 2, 2022. The copyright holder for this preprint

(which was not certified by peer review) is the author/funder, who has granted medRxiv a license to display the preprint in perpetuity.

It is made available under a CC-BY-NC 4.0 International license .

\section{Sensitivity analyses}

For rostral anterior cingulate thickness asymmetry, there were three datasets in the primary metaanalysis which had outlier case-control effect sizes when compared to the meta-analyzed effect (see Methods). After excluding these datasets and repeating the meta-analysis for this AI, the case-control difference remained, with the same directionality $\left(d=-0.073, z=-3.51, p=4.5 \times 10^{-4}\right)$ (Table S7). For middle temporal gyrus thickness asymmetry, the exclusion of two outlier datasets also yielded a similar result compared to the primary analysis $\left(d=-0.079, z=-3.44, p=5.9 \times 10^{-4}\right)$, again with the same directionality (Table S7). In models that included either handedness, ICV, both handedness and ICV, or age ${ }^{2}$ as additional covariates (models 2-5), the results for both of these regional AIs remained nominally significant, although the case-control effect for middle temporal gyrus thickness asymmetry decreased in most of these models, whereas it increased for rostral anterior cingulate thickness asymmetry (Table S8).

\section{Medication group differences}

Rostral anterior cingulate thickness asymmetry did not differ between affected individuals across medication groups (model 6) (Table S9). For the middle temporal gyrus, there was a nominally significant increase in average rightward asymmetry in affected individuals taking first-generation versus second generation antipsychotics at the time of scanning $\left(d=-0.21, z=-2.56, p=0.011, p_{\mathrm{FDR}}=\right.$ 0.13 ), i.e., this was not significant after multiple testing correction (Table S9).

\section{Correlations of asymmetries with clinical variables}

We found nominally significant correlations between rostral anterior cingulate thickness asymmetry and negative symptom severity measured with SANS $\left(r=0.049, z=2.08, p=0.038, p_{\mathrm{FDR}}=0.32\right.$, decreased rightward asymmetry with higher negative symptom rate) (Table S10A) and between middle temporal gyrus thickness asymmetry and duration of illness $(r=-0.048, z=-1.97, p=0.049$, $p_{\mathrm{FDR}}=0.32$, increased rightward asymmetry with longer duration of illness) (Table $\mathrm{S} 10 \mathrm{~B}$ ), but these correlations did not remain significant when correcting for multiple testing. No correlations with chlorpromazine-equivalent medication dose, age at onset, PANSS scores (total or positive and negative subscales), or SAPS or SANS scores, were found for either the rostral anterior cingulate thickness asymmetry or middle temporal gyrus thickness asymmetry (Table S10).

\section{Age- and sex-specific effects}

In secondary analyses across all AIs using models with interaction terms, we found a significant diagnosis-by-age interaction (model 8 ) for pallidum volume asymmetry $(d=0.081, z=3.26, p=1.1 \mathrm{x}$ $10^{-3}, p_{\mathrm{FDR}}=9.0 \times 10^{-3}$, stronger leftward asymmetry with higher age in cases) (Table S11-S12A, Figure S9). This association was driven by a significantly decreased average leftward asymmetry with 
medRxiv preprint doi: https://doi.org/10.1101/2022.03.01.22271652; this version posted March 2, 2022. The copyright holder for this preprint

(which was not certified by peer review) is the author/funder, who has granted medRxiv a license to display the preprint in perpetuity.

It is made available under a CC-BY-NC 4.0 International license .

increasing age in controls $\left(r=-0.077, p=1.1 \times 10^{-3}\right)$ that was not present in affected individuals (Table S12B; Figure S10). In terms of the corresponding unilateral effects, left and right pallidum volume decreased with increasing age in individuals with schizophrenia (L: $r=-0.17, p=4.7 \times 10^{-9}$; $\left.\mathrm{R}: r=-0.20, p=4.7 \times 10^{-21}\right)$ and unaffected controls (L: $r=-0.27, p=2.1 \times 10^{-22} ; \mathrm{R}: r=-0.24, p=6.2$ $\mathrm{x} 10^{-17}$ ), but the two groups differed with respect to the side showing the stronger effect (Table S12B). No significant sex-by-diagnosis interactions were found (model 9) (Table S13).

\section{Multivariate analysis of case-control asymmetry differences}

Considering all 76 regional structural brain AIs simultaneously in a multivariate model, applied to the 14 datasets for which individual-level data were available to the central analysis team (935 affected individuals and 1,094 controls), there was a significant multivariate structural brain asymmetry difference between cases and controls that accounted for roughly $7 \%$ of the variance considered across all 76 AIs (Wilks' $\Lambda=0.932$, approximate $F(76,1950)=1.87, p=1.25 \times 10^{-5}$ ). Only three of the $F$-statistics resulting from one million label-swapping permutations (see Methods) were larger than the $F$-statistic from the true analysis, resulting in a permutation $p=3.0 \times 10^{-6}$. We also derived univariate (ANCOVA) association statistics from the multivariate model to understand which AIs contributed most to the significant multivariate association. The structural AIs that showed nominally significant, univariate case-control differences in the 14 datasets available for this analysis were those for pallidum volume, nucleus accumbens volume, and eight regional surface area or thickness measures distributed widely over the cerebral cortex (Table 3). These did not include the two cortical regional AIs that showed significant case-control differences in the meta-analysis over all 45 casecontrol datasets, but did include AIs of other language-related regions of the temporal lobe: superior temporal sulcus surface area asymmetry and transverse temporal gyrus thickness asymmetry (Table $3)$.

\section{Discussion}

In this study, we investigated group differences in structural brain asymmetries between individuals with schizophrenia and unaffected controls, in the largest sample to date. The large sample size offered unprecedented statistical power to identify group differences, and to measure their effect sizes (35). Subtle differences of regional asymmetry were found for rostral anterior cingulate thickness, middle temporal gyrus thickness, and pallidum volume (the latter in older individuals). The Cohen's $d$ effect sizes were less than 0.1 ; i.e., very small (70). In light of previous large-scale analyses of bilateral cortical and subcortical alterations in schizophrenia $(44,45)$, our results suggest that morphometric alterations in this disorder are largely the same for the left and right hemispheres, involving only subtle asymmetrical effects at the group average level. This suggests that effect sizes 
medRxiv preprint doi: https://doi.org/10.1101/2022.03.01.22271652; this version posted March 2, 2022. The copyright holder for this preprint

(which was not certified by peer review) is the author/funder, who has granted medRxiv a license to display the preprint in perpetuity.

It is made available under a CC-BY-NC 4.0 International license .

of brain asymmetry differences in schizophrenia reported in earlier, much smaller studies (see Introduction), are likely to have been overestimated. Nonetheless, in a multivariate context, $7 \%$ of the total variance across all regional asymmetries was explained by case-control status.

Subtle group differences of asymmetry in terms of macro-anatomic features, such as those studied here, may reflect substantial effects at other neurobiological levels with more functional relevance for disorder symptoms - for example molecular, cytoarchitectonic and/or circuit levels (71-73). The middle temporal gyrus is prominently involved in the brain's language network (69), so that our univariate finding of lower left-sided cortical thickness in schizophrenia in this region is broadly consistent with a prominent theory in the literature: that left-hemisphere language dominance may be affected in this disorder $(10,11)$. Cortical thinning of the left-hemispheric middle temporal gyrus has been associated with auditory verbal hallucinations in schizophrenia (74), and reported to be present also in individuals with first-episode schizophrenia and high familial risk for the disorder $(75,76)$. In terms of grey matter volume, an opposite pattern (reduced right, increased left) has been reported for the middle temporal gyrus in putatively at-risk children compared to typically developing children (77). However, volume measures confound cortical thickness and surface area, and since these two aspects of cortical anatomy are known to vary substantially independently $(26,78,79)$, it is unclear how these earlier volume-based findings may relate to the present findings based on cortical thickness asymmetry. Again, earlier findings in smaller samples may have been false positives with overestimated effect sizes.

The rostral anterior cingulate cortex is an important hub in emotional and cognitive control (80), both of which are often affected in schizophrenia. In this region we observed a thinner left-sided cortex in affected individuals than controls on average, which was more pronounced than on the right side. This may be consistent with a previous study where adolescent/young adult relatives of individuals with schizophrenia showed a longitudinal decline of gray matter volume in the left rostral anterior cingulate cortex compared to controls (81). It is therefore possible that asymmetrical differences in this region emerge before schizophrenia onset, although the previous study included only 23 relatives, so its reported effects remain equivocal, and it used volume rather than thickness measures. In the present study, we saw no evidence for an age*diagnosis interaction effect for this regional thickness asymmetry, which is consistent with a pre-onset alteration that subsequently remains stable through adulthood.

Multivariate analysis in 14 of the datasets, for which individual-level data were available, resulted in a highly significant case-control difference. Various regional asymmetries contributed to this multivariate association, with pallidum volume asymmetry showing the largest individual contribution. Pallidum volume asymmetry was especially associated with schizophrenia in older 
medRxiv preprint doi: https://doi.org/10.1101/2022.03.01.22271652; this version posted March 2, 2022. The copyright holder for this preprint

(which was not certified by peer review) is the author/funder, who has granted medRxiv a license to display the preprint in perpetuity.

It is made available under a CC-BY-NC 4.0 International license .

individuals, as observed in secondary testing of univariate interaction models across all 45 casecontrol datasets. Larger pallidum volume in schizophrenia compared to controls - with a stronger effect in the left hemisphere - has been reported before $(40,41,45,82)$, although some datasets in our analysis partly overlapped with three of these studies $(40,41,45)$. An age-dependent relationship between familial risk for schizophrenia and larger left pallidum volume has also been described in a small study of young adults (83) - this suggests that alterations of pallidum asymmetry might already be present in a prodromal stage of the disease. However, in the present study, the group difference in pallidum volume was absent in younger individuals and became more apparent in older adults. This also explains why the association was not significant in the primary univariate meta-analysis of all datasets together, i.e. it was driven by a subset of datasets that included older individuals, and that were also available for multivariate analysis (Figure S10). The pallidum is prominently involved in reward and motivation (84), and impaired reward anticipation and a loss of motivation are wellknown negative symptoms of schizophrenia (85). However, how pallidum structural asymmetry may relate to functional disorder-relevant changes remains unknown.

We found a tentative difference of middle temporal gyrus thickness asymmetry between individuals who were taking first-generation versus second-generation antipsychotics, with a relatively larger effect size $(d=-0.21)$ than any case-control differences from the primary analysis. This result suggests that first-generation antipsychotics have a stronger effect on left middle temporal gyrus thickness than second-generation antipsychotics, which could relate to molecular or cellular hemispheric differences. Alternatively, this regional asymmetry may relate to clinical differences of disorder presentation which affect treatment choices. Indeed, we saw nominally significant evidence that this same asymmetry relates to illness duration. However, the medication subgroup analyses were limited by relatively small sample sizes compared to the primary case-control analysis, and this particular association did not survive multiple testing correction. Also, medication status was based on medication use at the time of scanning, and did not include information on previously used antipsychotics. This association therefore remains tentative until replicated.

Various brain regional asymmetries have shown significant heritability in a recent genome-wide analysis of general population data (26), including rostral anterior cingulate thickness asymmetry and pallidum volume asymmetry (but not middle temporal gyrus thickness asymmetry). When polygenic risk for schizophrenia was assessed with respect to these heritable asymmetries in a multivariate analysis (27), one of the strongest associations was with rostral anterior cingulate thickness asymmetry. The direction of that effect was consistent with the present study, i.e. a rightward shift of asymmetry with increased polygenic risk for schizophrenia. In contrast, pallidum volume asymmetry showed little relation to schizophrenia polygenic risk (27), suggesting non-heritable contributions to this association. These genetic findings were established with adult general population data (UK 
medRxiv preprint doi: https://doi.org/10.1101/2022.03.01.22271652; this version posted March 2, 2022. The copyright holder for this preprint

(which was not certified by peer review) is the author/funder, who has granted medRxiv a license to display the preprint in perpetuity.

It is made available under a CC-BY-NC 4.0 International license .

Biobank) (27), but together with the current case-control findings, they indicate that altered rostral anterior cingulate thickness asymmetry may be a link between genetic susceptibility and disorder presentation. Left-right asymmetry of the brain originates during development in utero (71, 86-91), and specific genomic loci that affect brain asymmetry have recently been identified $(26,92)$. Some of the implicated genes may be involved in patterning the left-right axis of the embryonic or fetal brain, and genes expressed at different levels on the left and right sides of the embryonic central nervous system were found to be particularly likely to affect schizophrenia susceptibility (86). However, other genes may affect brain asymmetry as it changes throughout the lifespan $(2,93)$ and therefore may affect susceptibility to asymmetry-associated disorders later in life.

This was the largest study of structural brain asymmetries in schizophrenia to date, and made use of a single image processing and analysis pipeline to support analysis across multiple datasets. However, several limitations also apply. First, schizophrenia is a highly heterogeneous disorder covering a range of possible symptoms, which may correspond to differing underlying disease mechanisms. Our primary analysis only considered case-control group average differences, and in secondary analyses, we did not find significant correlations of asymmetries with major clinical variables within cases after adjusting for multiple testing - including age at onset, duration of illness, and symptom scores. More detailed clinical data would be useful to gather in future large-scale studies of structural asymmetries. Second, we used cross-sectional datasets, limiting the possible interpretation with respect to causeeffect relations or longitudinal changes. Third, we used macro-anatomical brain atlases for both the cortical and subcortical structures, which is the most feasible approach for large-scale analysis across multiple datasets, but limits spatial resolution. With higher resolution mapping, regions that showed negative results in our study may harbor more focal case-control asymmetry differences, which could be revealed for example through vertex-wise cortical mapping $(58,92,94)$, or subcortical partitioning into subfields or nuclei. Fourth, data for several variables were only available from a limited number of study sites (medication, handedness, clinical variables), reducing the sample size and thus statistical power in these secondary analyses. Fifth, this study focused on group average differences, but individual-level deviations in affected individuals may be highly heterogeneous and not well captured by group-average approaches (95). Future studies may investigate individual or patient subgroup asymmetry deviations from a normative range or structural pattern, which may deliver clinical utility, for example through contributing to diagnosis or prognosis. This concept has shown promising results in recent studies even in smaller samples $(95,96)$. The small group-average effects that we identified in the present study are unlikely to have clinical utility when considered in isolation, although they may contribute to multivariate prediction models in future research, for example when considering brain features across multiple imaging modalities. 
medRxiv preprint doi: https://doi.org/10.1101/2022.03.01.22271652; this version posted March 2, 2022. The copyright holder for this preprint

(which was not certified by peer review) is the author/funder, who has granted medRxiv a license to display the preprint in perpetuity.

It is made available under a CC-BY-NC 4.0 International license.

In summary, we performed the largest study of asymmetry differences between individuals with schizophrenia and unaffected controls to date. Effect sizes were small, but several regional casecontrol asymmetry differences in cortical thickness and subcortical volume were suggested, and multivariate analysis indicated that $7 \%$ of variation across all regional asymmetries could be explained by the case-control group difference. Our findings therefore support a long-standing theory that the brain's asymmetry can be different in schizophrenia $(10,11)$, even if earlier studies in smaller samples were likely to have over-estimated the effect sizes in relation to structural asymmetry. Altered asymmetry in schizophrenia may conceivably occur during development through disruption of a genetically regulated program of asymmetrical brain development, and/or through different trajectories of lifespan-related changes in brain asymmetries. The specific regions implicated here provide targets for future research on the molecular and cellular basis of altered lateralized cognitive functions in schizophrenia, which may ultimately help to identify pathophysiological mechanisms. 
medRxiv preprint doi: https://doi.org/10.1101/2022.03.01.22271652; this version posted March 2, 2022. The copyright holder for this preprint (which was not certified by peer review) is the author/funder, who has granted medRxiv a license to display the preprint in perpetuity. It is made available under a CC-BY-NC 4.0 International license.

\section{Acknowledgments}

The ENIGMA project is in part supported by the National Institute of Biomedical Imaging and Bioengineering of the National Institutes of Health (NIH) (Grant No. U54EB020403). The content is solely the responsibility of the authors and does not necessarily represent the official views of the National Institutes of Health. DS, MCP, SEF and CF [ENIGMA-Laterality] were funded by the Max Planck Society (Germany). RA-A [PAFIP] is funded by a Miguel Servet contract from the Carlos III Health Institute (CP18/00003). JV-B [PAFIP] has received unrestricted research funding from Instituto de Investigación sanitaria Valdecilla (IDIVAL): INT/A21/10, INT/A20/04. DA [TOP] is funded by the South-Eastern Norway Regional Health Authority (grants 2019107 and 2020086). LTW [TOP] is funded by The Research Council of Norway (223273, 300767), the South-Eastern Norway Regional Health Authority (2019101), and the European Research Council under the European Union's Horizon 2020 research and Innovation program (ERC StG, Grant 802998). OAA [TOP] is funded by the Research Council of Norway (\#223273, \#275054) and KG Jebsen Stiftelsen, South East Norway Health Authority (2017-112, 2019-108). PK [MPRC, Huilong] received support from NIH grants R01MH123163 and R01EB015611. MJG [ASRB, IGP] received funding from NHMRC Project Grants 630471, 1051672, 1081603. CP [ASRB] was supported by a National Health and Medical Research Council (NHMRC) Senior Principal Research Fellowship (1105825), and NHMRC L3 Investigator Grant (1196508). VDC [FBIRN, COBRE] was funded by NIH grants R01MH118695 and NSF 2112455. JMF [FBIRN] was funded by a Senior Research Career Scientist Award, Department of Veterans Affairs. PF-C [FIDMAG] is funded by CIBERSAM and by Instituto de Salud Carlos III, co-funded by European Union (ERDF/ESF, 'Investing in your future'): Sara Borrell Research contract (CD19/00149). GS [RomeSL] was funded by Italian Ministry of Health RC17-1819-20-21/A grants. ANV [CAMH] currently receives funding from the National Institute of Mental Health, Canadian Institutes of Health Research, Canada Foundation for Innovation, CAMH Foundation, and the University of Toronto. KS [IMH] received support from research grants from the National Healthcare Group, Singapore (SIG/05004; SIG/05028), and the Singapore Bioimaging Consortium (RP C009/2006). Y-CC [JBNU] was supported by a grant of the Korean Mental Health Technology R\&D Project, Ministry of Health \& Welfare, Republic of Korea (HL19C0015) and a grant of the Korea Health Technology R\&D Project through the Korea Health Industry Development Institute (KHIDI), funded by the Ministry of Health \& Welfare, Republic of Korea (HI18C2383). UD [FOR2107 Münster] was funded by the German Research Foundation (DFG, grant FOR2107 DA1151/5-1 and DA1151/5-2; SFB-TRR58, Projects C09 and Z02) and the Interdisciplinary Center for Clinical Research (IZKF) of the medical faculty of Münster (grant Dan3/012/17). JMS [COBRE] was funded by NIH grant 1P20RR021938-01. ARM [COBRE] received funding from NIH grants P30GM122734 and R01MH101512. CMD-C [Madrid] has received funding from Instituto de Salud Carlos III, Spanish Ministry of Science and Innovation (PI17/00481, PI20/00721, JR19/00024). SCe 
medRxiv preprint doi: https://doi.org/10.1101/2022.03.01.22271652; this version posted March 2, 2022. The copyright holder for this preprint (which was not certified by peer review) is the author/funder, who has granted medRxiv a license to display the preprint in perpetuity. It is made available under a CC-BY-NC 4.0 International license .

[KaSP] received funding from the Swedish Research Council (Grant No. 523-2014-3467). MKir [Zurich] acknowledges funding from the Swiss National Science Foundation (P2SKP3_178175). TH [ESO] was supported by funding from the Canadian Institutes of Health Research (142255), Ministry of Health of the Czech Republic (16-32791A, NU20-04-00393), and Brain \& Behavior Research Foundation Young and Independent Investigator Awards. AJam [Oxford] was supported by MRC grant G0500092. PH [SWIFT] is supported by a NARSAD grant from the Brain \& Behavior Research Foundation (28445) and by a Research Grant from the Novartis Foundation (20A058). RCG [UPENN] received funding through NIH grants 1R01MH117014 and 1R01MH119219. NJ [ENIGMA] is funded by NIH grant R01MH117601. SEM [ENIGMA] is supported in part by Australian NHMRC APP1172917. JAT [FBIRN, MCIC, COBRE] is supported by NIH grant R01MH121246. Further acknowledgments specific to datasets are listed in the Supplementary Information.

\section{Disclosures}

OAA is a consultant to HealthLytix. JB has received royalties from UpToDate. DHM is a consultant for Recognify Life Sciences Inc., and Syndesi Therapeutics. AB received consulting fees by Biogen and lecture fees by Otsuka, Janssen, and Lundbeck. CMD-C has received honoraria from Exeltis and Sanofi. CAr has been a consultant to or has received honoraria or grants from Acadia, Angelini, Boehringer, Gedeon Richter, Janssen Cilag, Lundbeck, Minerva, Otsuka, Pfizer, Roche, Sage, Servier, Shire, Schering Plough, Sumitomo Dainippon Pharma, Sunovion and Takeda. SK receives royalties for cognitive test and training software from Schuhfried, Austria. BF has received educational speaking fees from Medice $\mathrm{GmbH}$.

\section{Author contributions}

Study conception and design: DS, MCP, SEF, BF, DCG, RCG, RH, NJ, SEM, PMT, JAT, TGMvE, CF; Data acquisition/analysis: DS, MCP, MF, JM, KM, SMCdZ, NEMvH, WC, HEHP, RSK, RA-A, VO-GdlF, DT-G, JV-B, BC-F, DA, AD, LTW, IA, OAA, EGJ, PK, JMB, SVC, PTM, BJM, YQ, PER, US, RJS, VJC, MJG, FAH, CML, CP, CSW, TWW, LdH, KB, J-KP, KGR, FSt, AJan, TTJK, IN, BK, OG, TDS, JB, DHM, AP, VDC, JMF, SGP, JC, YT, ZW, HX, FF, SE, PF-C, MAG-L, AG-P, RS, SS, EP-C, VC, FP, DV, NB, GS, SM, TvA, EWD, ANV, KS, SCi, PD, RMM, W-SK, Y-CC, CAn, ASc, SB, AMMcI, HCW, SML, SdP, HKL, FSc, RE, DG, RL, UD, JTE, KR-M, JMS, ARM, LAA, LF, GP, AB, CMD-C, JJ, NGL, CAr, AST, IL, SCe, CMS, FG, MKir, SK, TH, ASk, FSp, MKim, YBK, SO, JSK, AJam, CK, MS, VO, AU, FMH, DJS, HST, AMD-Z, JAP-Z, CL-J, SH, EJ, 
medRxiv preprint doi: https://doi.org/10.1101/2022.03.01.22271652; this version posted March 2, 2022. The copyright holder for this preprint (which was not certified by peer review) is the author/funder, who has granted medRxiv a license to display the preprint in perpetuity.

It is made available under a CC-BY-NC 4.0 International license.

WS, PH, DCG, RCG, RH, JAT, TGMvE; Drafting of the manuscript: DS, CF; Critical revision of the manuscript: DS, MCP, MF, JM, KM, SMCdZ, NEMvH, WC, HEHP, RSK, RA-A, VO-GdIF, DT-G, JV-B, BC-F, DA, AD, LTW, IA, OAA, EGJ, PK, JMB, SVC, PTM, BJM, YQ, PER, US, RJS, VJC, MJG, FAH, CML, CP, CSW, TWW, LdH, KB, J-KP, KGR, FSt, AJan, TTJK, IN, BK, OG, TDS, JB, DHM, AP, VDC, JMF, SGP, JC, YT, ZW, HX, FF, SE, PF-C, MAG-L, AG-P, RS, SS, EP-C, VC, FP, DV, NB, GS, SM, TvA, EWD, ANV, KS, SCi, PD, RMM, W-SK, Y-CC, CAn, ASc, SB, AMMcI, HCW, SML, SdP, HKL, FSc, RE, DG, RL, UD, JTE, KR-M, JMS, ARM, LAA, LF, GP, AB, CMD-C, JJ, NGL, CAr, AST, IL, SCe, CMS, FG, MKir, SK, TH, ASk, FSp, MKim, YBK, SO, JSK, AJam, CK, MS, VO, AU, FMH, DJS, HST, AMD-Z, JAP-Z, CL-J, SH, EJ, WS, PH, SEF, BF, DCG, RCG, RH, NJ, EL, SEM, PMT, JAT, TGMvE, CF. 


\section{Figures}

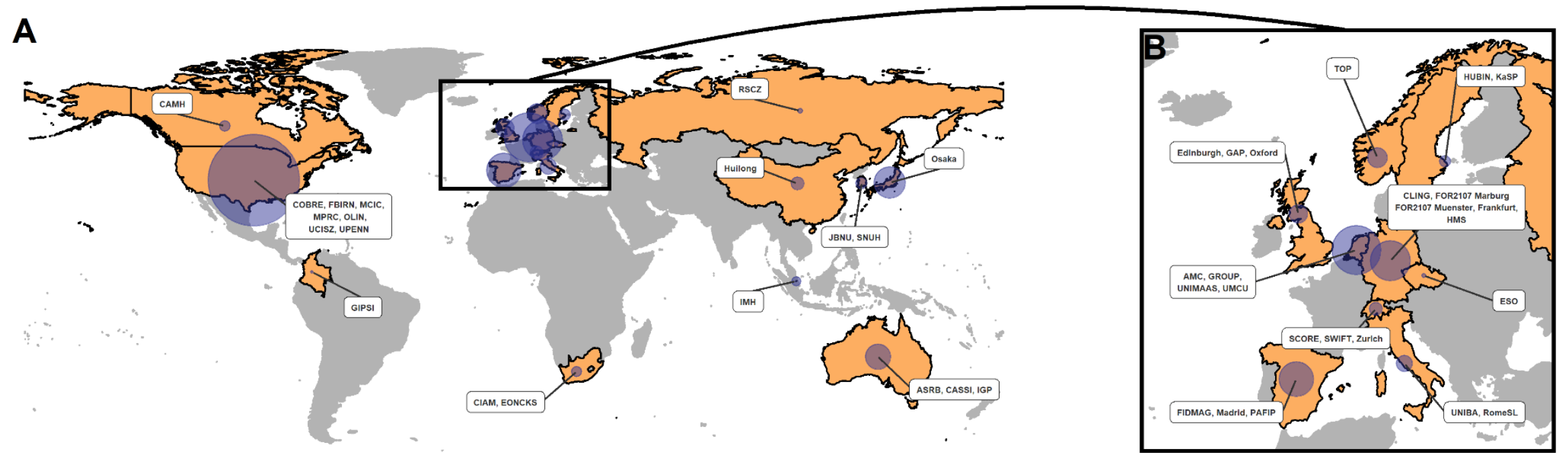

Figure 1. Geographic origin of included datasets. A) Countries from which one or more datasets originate are highlighted in the world map, with dataset names included in labels. The relative sample size of datasets per country is indicated by blue circles. B) Zoomed map of Europe. For more details, see Table 1. Figure generated in R using packages rnaturalearth, ggrepel, and $s f$. 

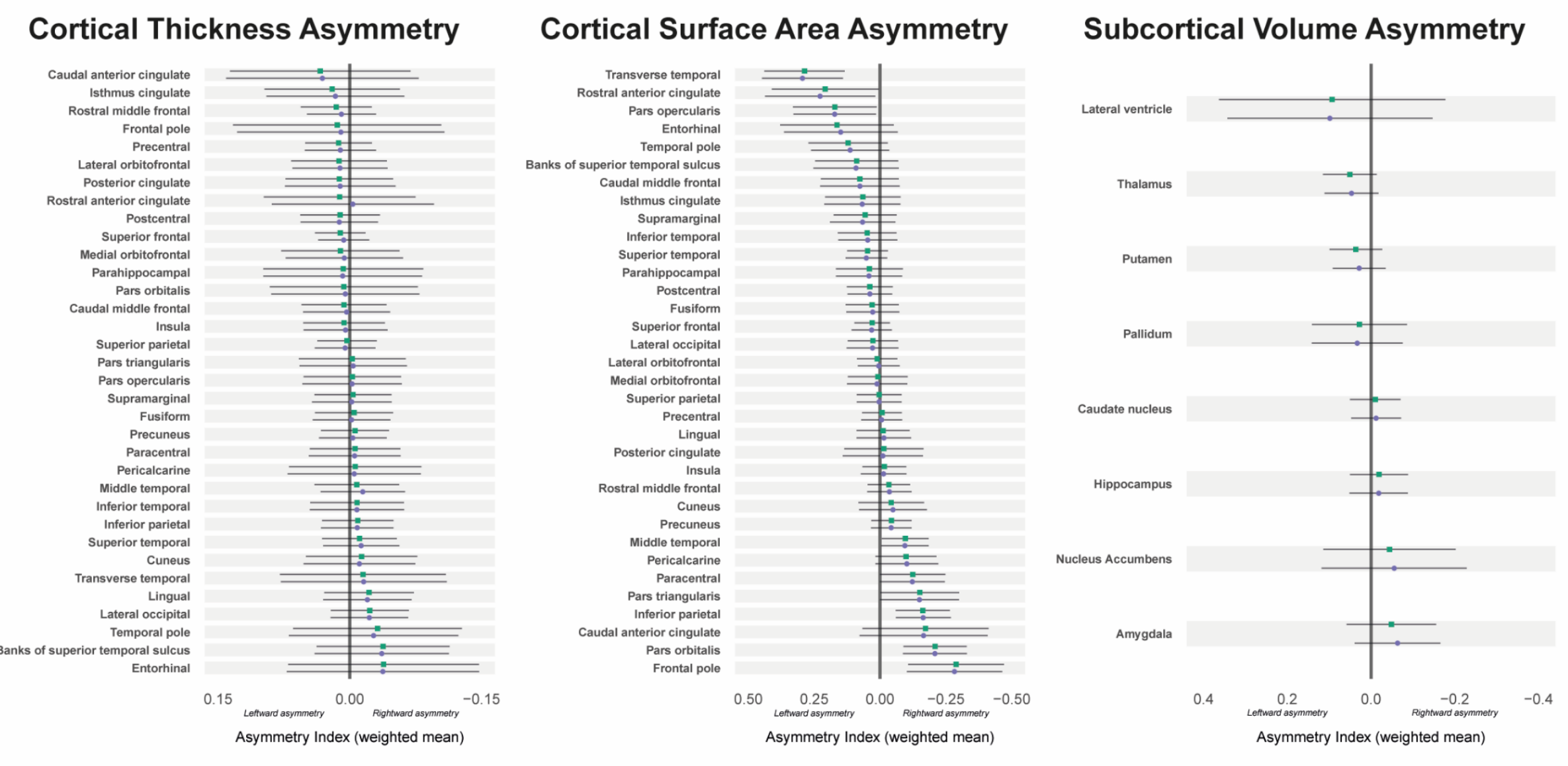

Figure 2. Average structural asymmetries of the brain in individuals with schizophrenia and unaffected controls. For each bilaterally paired structural measure, the mean asymmetry index (AI) across datasets, weighted by sample size, is shown for individuals with schizophrenia (purple) and unaffected controls (green). A positive AI indicates left > right asymmetry, whereas a negative AI indicates right > left asymmetry. Error bars show pooled standard deviations. 


\section{Cortical Thickness Asymmetry}
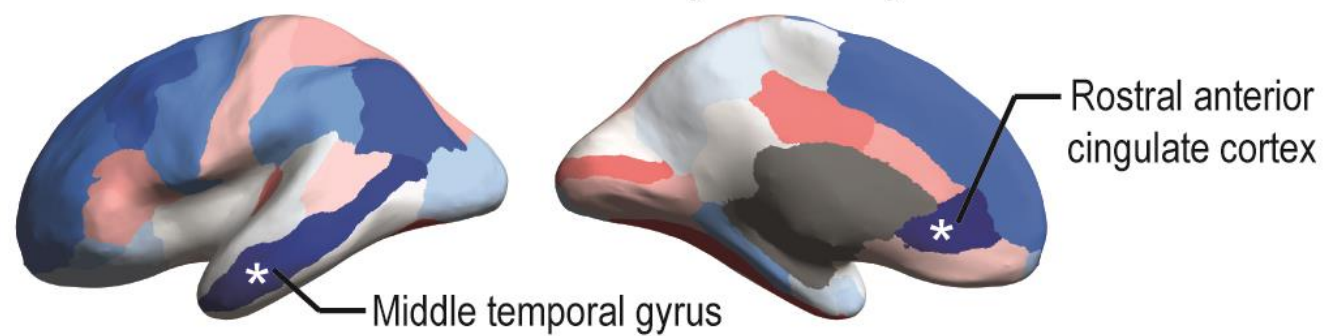

Lateral view

Medial view

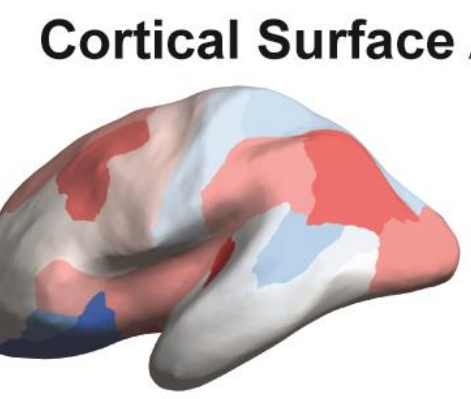

Lateral view

Subcortical Volume Asymmetry

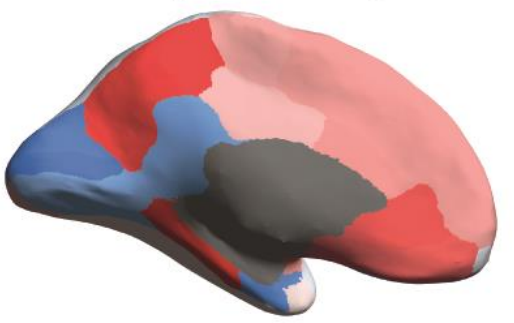

Medial view

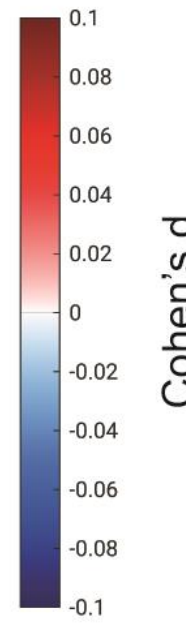

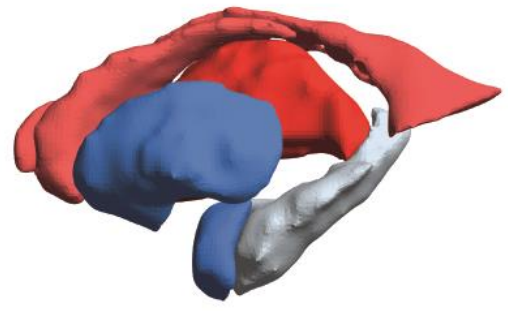

Lateral view

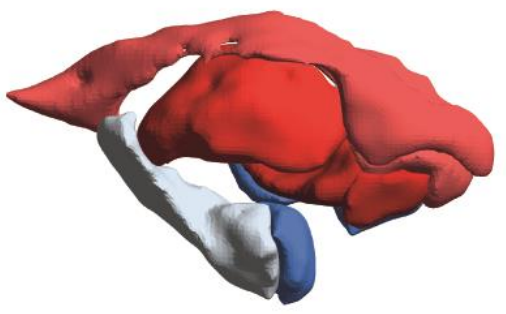

Medial view

Figure 3. Map of cortical and subcortical asymmetry differences between individuals with schizophrenia and unaffected controls. Cohen's $d$ effect sizes from random-effects meta-analysis are projected on inflated left hemisphere cortical surface models (for cortical thickness and surface area) or subcortical structures (for subcortical volumes). Positive effects are shown in red shades (larger leftward or smaller rightward asymmetry in cases versus controls), while negative effects are shown in blue shades (smaller leftward or larger rightward asymmetry in cases versus controls). Gray shades indicate masked out structures. See also Figure 2 and Table S4 for directions of effects. Regions significant at $p_{\mathrm{FDR}}<0.05$ are labelled and marked with asterisks. 
medRxiv preprint doi: https://doi.org/10.1101/2022.03.01.22271652; this version posted March 2, 2022. The copyright holder for this preprint (which was not certified by peer review) is the author/funder, who has granted medRxiv a license to display the preprint in perpetuity.

It is made available under a CC-BY-NC 4.0 International license .

Table 1. Overview of the ENIGMA-Schizophrenia datasets.

\begin{tabular}{|c|c|c|c|c|c|c|}
\hline \multirow[b]{2}{*}{ Dataset } & \multirow[b]{2}{*}{ Country } & \multirow[b]{2}{*}{ N Total } & \multicolumn{2}{|c|}{ Individuals with Schizophrenia } & \multicolumn{2}{|c|}{ Unaffected Controls } \\
\hline & & & $\mathbf{N} \mathbf{M} / \mathbf{F}$ & Mean age (years) & $\mathbf{N} \mathbf{M} / \mathbf{F}$ & Mean age (years) \\
\hline AMC & Netherlands & 405 & $180 / 26$ & 22.2 & $130 / 69$ & 23.5 \\
\hline ASRB* & Australia & 429 & $177 / 86$ & 38.6 & $79 / 87$ & 39.3 \\
\hline CAMH & Canada & 264 & $70 / 48$ & 44.0 & $77 / 69$ & 43.6 \\
\hline CASSI* & Australia & 116 & $35 / 18$ & 35.2 & $33 / 30$ & 30.5 \\
\hline CIAM & South Africa & 51 & $13 / 8$ & 31.1 & $16 / 14$ & 26.6 \\
\hline CLING & Germany & 371 & $35 / 13$ & 32.4 & $132 / 191$ & 25.2 \\
\hline COBRE* & United States & 143 & $60 / 13$ & 37.4 & $50 / 20$ & 35.7 \\
\hline EdinburghEHRS & United Kingdom & 67 & $19 / 12$ & 21.8 & $17 / 19$ & 21.2 \\
\hline EdinburghFunc & United Kingdom & 60 & $11 / 14$ & 37.2 & $18 / 17$ & 37.5 \\
\hline EdinburghSFMH & United Kingdom & 76 & $23 / 12$ & 37.5 & $23 / 18$ & 38.2 \\
\hline EONCKS* & South Africa & 200 & $74 / 34$ & 34.2 & $51 / 41$ & 31.9 \\
\hline ESO* & Czech Republic & 80 & $20 / 20$ & 29.5 & $20 / 20$ & 29.1 \\
\hline FBIRN & United States & 359 & $139 / 46$ & 39.0 & $124 / 50$ & 37.5 \\
\hline FIDMAG & Spain & 283 & $124 / 36$ & 39.6 & $54 / 69$ & 37.5 \\
\hline FOR2107 Marburg* & Germany & 403 & $23 / 14$ & 37.2 & $143 / 223$ & 34.0 \\
\hline FOR2107 Muenster* & Germany & 163 & $4 / 4$ & 33.4 & $60 / 95$ & 27.0 \\
\hline Frankfurt & Germany & 59 & $20 / 9$ & 38.1 & $13 / 17$ & 35.2 \\
\hline GAP & United Kingdom & 209 & $85 / 37$ & 27.5 & $32 / 55$ & 25.9 \\
\hline GIPSI & Colombia & 43 & $35 / 8$ & 33.5 & - & - \\
\hline GROUP & Netherlands & 271 & $59 / 29$ & 28.2 & $83 / 100$ & 30.1 \\
\hline HMS & Germany & 101 & $32 / 14$ & 28.4 & $28 / 27$ & 35.4 \\
\hline HUBIN & Sweden & 196 & $70 / 24$ & 41.7 & $69 / 33$ & 42.0 \\
\hline Huilong & China & 333 & $133 / 112$ & 25.5 & $49 / 39$ & 27.7 \\
\hline IGP* & Australia & 138 & $40 / 28$ & 41.7 & $38 / 32$ & 36.0 \\
\hline $\mathrm{IMH}^{*}$ & Singapore & 227 & $105 / 46$ & 33.1 & $47 / 29$ & 31.8 \\
\hline JBNU & South Korea & 208 & $57 / 37$ & 39.3 & $48 / 66$ & 41.4 \\
\hline KaSP & Sweden & 88 & $34 / 22$ & 30.3 & $15 / 17$ & 27.5 \\
\hline Madrid & Spain & 105 & $17 / 4$ & 16.2 & $59 / 25$ & 11.8 \\
\hline MCIC & United States & 311 & $113 / 35$ & 32.9 & $101 / 62$ & 31.4 \\
\hline MPRC* & United States & 437 & $128 / 78$ & 35.4 & $96 / 135$ & 37.1 \\
\hline OLIN* & United States & 868 & $174 / 138$ & 37.7 & $310 / 246$ & 37.6 \\
\hline Osaka & Japan & 855 & $118 / 98$ & 36.1 & $318 / 321$ & 34.1 \\
\hline Oxford & United Kingdom & 74 & $24 / 17$ & 16.3 & $15 / 18$ & 16.1 \\
\hline PAFIP & Spain & 556 & $214 / 138$ & 29.9 & $127 / 77$ & 29.2 \\
\hline RomeSL & Italy & 280 & $110 / 54$ & 39.4 & $73 / 43$ & 37.5 \\
\hline RSCZ & Russia & 98 & $46 / 0$ & 22.2 & $52 / 0$ & 22.3 \\
\hline SCORE & Switzerland & 205 & $117 / 44$ & 25.5 & $17 / 27$ & 25.5 \\
\hline SNUH & South Korea & 80 & $18 / 22$ & 22.9 & $20 / 20$ & 22.6 \\
\hline SWIFT & Switzerland & 37 & $17 / 7$ & 34.2 & $5 / 8$ & 29.3 \\
\hline TOP & Norway & 522 & $130 / 89$ & 32.0 & $159 / 144$ & 35.4 \\
\hline UCISZ* & United States & 57 & $22 / 5$ & 42.9 & $23 / 7$ & 41.4 \\
\hline UMCU & Netherlands & 600 & $236 / 79$ & 30.9 & $165 / 120$ & 32.9 \\
\hline UNIBA* & Italy & 143 & $54 / 19$ & 33.5 & $28 / 42$ & 26.6 \\
\hline UNIMAAS & Netherlands & 66 & $21 / 10$ & 28.3 & $24 / 11$ & 28.1 \\
\hline UPENN & United States & 370 & $105 / 72$ & 38.9 & $90 / 103$ & 36.4 \\
\hline Zurich* & Switzerland & 88 & $45 / 15$ & 30.5 & $18 / 10$ & 32.5 \\
\hline Total/Mean & & 11,095 & $3,386 / 1,694$ & 33.3 & 3,149 / 2,866 & 33.0 \\
\hline
\end{tabular}

All datasets are shown with their total sample sizes and the numbers of male (M) and female $(\mathrm{F})$ individuals with and without schizophrenia, as well as mean ages. For datasets marked with *, we had access to the individual-level data for the multivariate analysis. Exact sample sizes in the multivariate analysis are shown in Table S1C. 
Table 2. Significant brain regional asymmetry differences between individuals with schizophrenia and unaffected controls.

\begin{tabular}{|c|c|c|c|c|c|c|c|c|c|}
\hline \multirow[b]{2}{*}{ Structural AI } & \multicolumn{2}{|c|}{ Sample size (N) } & \multicolumn{2}{|c|}{ Mean AI (SD) } & \multicolumn{3}{|c|}{ Cohen's d effect size $[95 \% \mathrm{CI}]$} & \multicolumn{2}{|c|}{ Average asymmetry } \\
\hline & Control & Schizophrenia & Control & Schizophrenia & Left & Right & AI & Control & Schizophrenia \\
\hline $\begin{array}{l}\text { Rostral anterior cingulate cortex } \\
\text { (cortical thickness asymmetry) }\end{array}$ & 5,811 & 4,851 & $0.012(0.086)$ & $-0.0035(0.092)$ & $\begin{array}{c}-0.20 \\
{[-0.28,-0.11]}\end{array}$ & $\begin{array}{c}-0.094 \\
{[-0.15,-0.036]}\end{array}$ & $\begin{array}{c}-0.083 \\
{[-0.13,-0.032]}\end{array}$ & Leftward & $\begin{array}{l}\text { Reversed to } \\
\text { rightward }\end{array}$ \\
\hline $\begin{array}{l}\text { Middle temporal gyrus } \\
\text { (cortical thickness asymmetry) }\end{array}$ & 5,673 & 4,684 & $-0.0080(0.048)$ & $-0.015(0.048)$ & $\begin{array}{c}-0.41 \\
{[-0.50,-0.32]}\end{array}$ & $\begin{array}{c}-0.36 \\
{[-0.44,-0.27]}\end{array}$ & $\begin{array}{c}-0.074 \\
{[-0.12,-0.026]}\end{array}$ & Rightward & $\begin{array}{l}\text { Increased } \\
\text { rightward }\end{array}$ \\
\hline
\end{tabular}

Mean $\mathrm{AI}=$ weighted mean asymmetry index across datasets. $\mathrm{SD}=$ pooled standard deviation across datasets (positive mean indicates average leftward asymmetry, negative mean indicates average rightward asymmetry). Cohen's $d$ effect sizes are shown from separate meta-analysis of left-hemisphere, right-hemisphere and asymmetry index differences between cases and controls. No regional measures of cortical surface area asymmetry or subcortical volume asymmetry showed significant case-control differences after false discovery rate correction. 
medRxiv preprint doi: https://doi.org/10.1101/2022.03.01.22271652; this version posted March 2, 2022. The copyright holder for this preprint

(which was not certified by peer review) is the author/funder, who has granted medRxiv a license to display the preprint in perpetuity.

It is made available under a CC-BY-NC 4.0 International license .

Table 3. Multivariate analysis of case-control brain asymmetry differences between 935 individuals with schizophrenia and 1,094 controls for which individual-level data were available (14 datasets).

\begin{tabular}{lll}
\hline Structural asymmetry & Approximate $\boldsymbol{F}$ & $\boldsymbol{p}$ \\
\hline $\begin{array}{l}\text { Multivariate test (all regional cortical and subcortical } \\
\text { asymmetries) }\end{array}$ & 1.87 & $\begin{array}{l}\text { Nominal } p=1.25 \times 10^{-5} \\
\text { Permutation } p=3.0 \times 10^{-6}\end{array}$ \\
\hline & & \\
\hline Most significant univariate effects: & $\boldsymbol{F}$ & $\boldsymbol{p}$ \\
\hline Pallidum (volume asymmetry) & 29.1 & $7.8 \times 10^{-8}$ \\
Nucleus accumbens (volume asymmetry) & 9.3 & $2.3 \times 10^{-3}$ \\
Rostral middle frontal gyrus (surface area asymmetry) & 7.7 & $5.5 \times 10^{-3}$ \\
Parahippocampal gyrus (surface area asymmetry) & 7.2 & $7.4 \times 10^{-3}$ \\
Parahippocampal gyrus (thickness asymmetry) & 5.5 & 0.019 \\
Transverse temporal gyrus (thickness asymmetry) & 5.4 & 0.021 \\
Cuneus (surface area asymmetry) & 5.4 & 0.021 \\
Banks of superior temporal sulcus (surface area asymmetry) & 4.9 & 0.027 \\
Insula (surface area asymmetry) & 4.6 & 0.031 \\
Medial orbitofrontal cortex (thickness asymmetry) & 3.9 & 0.048 \\
\hline Resuls are shown for the mutivaiat MANCOVA over all asym
\end{tabular}

Results are shown for the multivariate MANCOVA over all asymmetries, and the specific asymmetries with nominal significance $(\mathrm{p}<0.05)$ in the corresponding univariate ANCOVAs, with their F statistics $(F)$ and p-values $(p)$. 
medRxiv preprint doi: https://doi.org/10.1101/2022.03.01.22271652; this version posted March 2, 2022. The copyright holder for this preprint

(which was not certified by peer review) is the author/funder, who has granted medRxiv a license to display the preprint in perpetuity.

It is made available under a CC-BY-NC 4.0 International license .

\section{References}

1. American Psychiatric Association (2013): Diagnostic and statistical manual of mental disorders. 5th edition ed. Arlington, VA: American Psychiatric Association.

2. Kong X-Z, Mathias SR, Guadalupe T, Glahn DC, Franke B, Crivello F, et al. (2018): Mapping cortical brain asymmetry in 17,141 healthy individuals worldwide via the ENIGMA Consortium. Proceedings of the National Academy of Sciences. 115:E5154-E5163.

3. Guadalupe T, Mathias SR, vanErp TGM, Whelan CD, Zwiers MP, Abe Y, et al. (2017): Human subcortical brain asymmetries in 15,847 people worldwide reveal effects of age and sex. Brain imaging and behavior. 11:1497-1514.

4. Karolis VR, Corbetta M, Thiebaut de Schotten M (2019): The architecture of functional lateralisation and its relationship to callosal connectivity in the human brain. Nature communications. 10:1417.

5. Toga AW, Thompson PM (2003): Mapping brain asymmetry. Nature reviews Neuroscience. 4:37-48.

6. Petty RG (1999): Structural asymmetries of the human brain and their disturbance in schizophrenia.

Schizophrenia bulletin. 25:121-139.

7. Ribolsi M, Daskalakis ZJ, Siracusano A, Koch G (2014): Abnormal asymmetry of brain connectivity in schizophrenia. Frontiers in human neuroscience. 8:1010.

8. Oertel-Knöchel V, Linden DE (2011): Cerebral asymmetry in schizophrenia. The Neuroscientist : a review journal bringing neurobiology, neurology and psychiatry. 17:456-467.

9. Berlim MT, Mattevi BS, Belmonte-de-Abreu P, Crow TJ (2003): The etiology of schizophrenia and the origin of language: overview of a theory. Comprehensive psychiatry. 44:7-14.

10. Crow TJ (1997): Schizophrenia as failure of hemispheric dominance for language. Trends in neurosciences. 20:339-343.

11. DeLisi LE, Sakuma M, Kushner M, Finer DL, Hoff AL, Crow TJ (1997): Anomalous cerebral asymmetry and language processing in schizophrenia. Schizophrenia bulletin. 23:255-271.

12. Ocklenburg S, Güntürkün O, Hugdahl K, Hirnstein M (2015): Laterality and mental disorders in the postgenomic age--A closer look at schizophrenia and language lateralization. Neuroscience and biobehavioral reviews. 59:100-110.

13. Sommer I, Ramsey N, Kahn R, Aleman A, Bouma A (2001): Handedness, language lateralisation and anatomical asymmetry in schizophrenia: meta-analysis. The British journal of psychiatry : the journal of mental science. 178:344-351.

14. Sommer IE, Ramsey NF, Kahn RS (2001): Language lateralization in schizophrenia, an fMRI study. Schizophrenia research. 52:57-67.

15. Ocklenburg S, Westerhausen R, Hirnstein M, Hugdahl K (2013): Auditory hallucinations and reduced language lateralization in schizophrenia: a meta-analysis of dichotic listening studies. Journal of the International Neuropsychological Society : JINS. 19:410-418.

16. Shapleske J, Rossell SL, Woodruff PW, David AS (1999): The planum temporale: a systematic, quantitative review of its structural, functional and clinical significance. Brain research Brain research reviews. 29:26-49. 17. Kawasaki Y, Suzuki M, Takahashi T, Nohara S, McGuire PK, Seto H, et al. (2008): Anomalous cerebral asymmetry in patients with schizophrenia demonstrated by voxel-based morphometry. Biological psychiatry. 63:793-800.

18. Hasan A, Kremer L, Gruber O, Schneider-Axmann T, Guse B, Reith W, et al. (2011): Planum temporale asymmetry to the right hemisphere in first-episode schizophrenia. Psychiatry research. 193:56-59.

19. Hirnstein M, Hugdahl K (2014): Excess of non-right-handedness in schizophrenia: meta-analysis of gender effects and potential biases in handedness assessment. The British journal of psychiatry : the journal of mental science. 205:260-267.

20. Deep-Soboslay A, Hyde TM, Callicott JP, Lener MS, Verchinski BA, Apud JA, et al. (2010): Handedness, heritability, neurocognition and brain asymmetry in schizophrenia. Brain : a journal of neurology. 133:31133122.

21. Dragovic M, Hammond G (2005): Handedness in schizophrenia: a quantitative review of evidence. Acta psychiatrica Scandinavica. 111:410-419.

22. DeLisi LE, Svetina C, Razi K, Shields G, Wellman N, Crow TJ (2002): Hand preference and hand skill in families with schizophrenia. Laterality. 7:321-332.

23. Orr KG, Cannon M, Gilvarry CM, Jones PB, Murray RM (1999): Schizophrenic patients and their firstdegree relatives show an excess of mixed-handedness. Schizophrenia research. 39:167-176.

24. Wiberg A, Ng M, Al Omran Y, Alfaro-Almagro F, McCarthy P, Marchini J, et al. (2019): Handedness, language areas and neuropsychiatric diseases: insights from brain imaging and genetics. Brain : a journal of neurology. 142:2938-2947.

25. Cuellar-Partida G, Tung JY, Eriksson N, Albrecht E, Aliev F, Andreassen OA, et al. (2020): Genome-wide association study identifies 48 common genetic variants associated with handedness. Nature human behaviour. 
medRxiv preprint doi: https://doi.org/10.1101/2022.03.01.22271652; this version posted March 2, 2022. The copyright holder for this preprint

(which was not certified by peer review) is the author/funder, who has granted medRxiv a license to display the preprint in perpetuity.

It is made available under a CC-BY-NC 4.0 International license .

26. Sha Z, Schijven D, Carrion-Castillo A, Joliot M, Mazoyer B, Fisher SE, et al. (2021): The genetic architecture of structural left-right asymmetry of the human brain. Nature human behaviour.

27. Sha Z, Schijven D, Francks C (2021): Patterns of brain asymmetry associated with polygenic risks for autism and schizophrenia implicate language and executive functions but not brain masculinization. Molecular psychiatry.

28. Park HY, Hwang JY, Jung WH, Shin NY, Shim G, Jang JH, et al. (2013): Altered asymmetry of the anterior cingulate cortex in subjects at genetic high risk for psychosis. Schizophrenia research. 150:512-518.

29. Li X, Alapati V, Jackson C, Xia S, Bertisch HC, Branch CA, et al. (2012): Structural abnormalities in language circuits in genetic high-risk subjects and schizophrenia patients. Psychiatry research. 201:182-189. 30. Shenton ME, Dickey CC, Frumin M, McCarley RW (2001): A review of MRI findings in schizophrenia. Schizophrenia research. 49:1-52.

31. DeRamus TP, Silva RF, Iraji A, Damaraju E, Belger A, Ford JM, et al. (2020): Covarying structural alterations in laterality of the temporal lobe in schizophrenia: A case for source-based laterality. NMR in biomedicine. 33:e4294.

32. Damme KSF, Vargas T, Calhoun V, Turner J, Mittal VA (2020): Global and Specific Cortical Volume Asymmetries in Individuals With Psychosis Risk Syndrome and Schizophrenia: A Mixed Cross-sectional and Longitudinal Perspective. Schizophrenia bulletin. 46:713-721.

33. Smiley JF, Hackett TA, Preuss TM, Bleiwas C, Figarsky K, Mann JJ, et al. (2013): Hemispheric asymmetry of primary auditory cortex and Heschl's gyrus in schizophrenia and nonpsychiatric brains. Psychiatry research. 214:435-443.

34. Sheng J, Zhu Y, Lu Z, Liu N, Huang N, Zhang Z, et al. (2013): Altered volume and lateralization of language-related regions in first-episode schizophrenia. Schizophrenia research. 148:168-174.

35. Button KS, Ioannidis JP, Mokrysz C, Nosek BA, Flint J, Robinson ES, et al. (2013): Power failure: why small sample size undermines the reliability of neuroscience. Nature reviews Neuroscience. 14:365-376. 36. Kong XZ, Francks C (2022): Reproducibility in the absence of selective reporting: An illustration from large-scale brain asymmetry research. Human brain mapping. 43:244-254.

37. Ettinger U, Picchioni M, Landau S, Matsumoto K, van Haren NE, Marshall N, et al. (2007): Magnetic resonance imaging of the thalamus and adhesio interthalamica in twins with schizophrenia. Archives of general psychiatry. 64:401-409.

38. Csernansky JG, Schindler MK, Splinter NR, Wang L, Gado M, Selemon LD, et al. (2004): Abnormalities of thalamic volume and shape in schizophrenia. The American journal of psychiatry. 161:896-902.

39. Boos HB, Aleman A, Cahn W, Hulshoff Pol H, Kahn RS (2007): Brain volumes in relatives of patients with schizophrenia: a meta-analysis. Archives of general psychiatry. 64:297-304.

40. Okada N, Fukunaga M, Yamashita F, Koshiyama D, Yamamori H, Ohi K, et al. (2016): Abnormal asymmetries in subcortical brain volume in schizophrenia. Molecular psychiatry. 21:1460-1466.

41. Okada N, Yahata N, Koshiyama D, Morita K, Sawada K, Kanata S, et al. (2018): Abnormal asymmetries in subcortical brain volume in early adolescents with subclinical psychotic experiences. Translational psychiatry. $8: 254$.

42. Thompson PM, Stein JL, Medland SE, Hibar DP, Vasquez AA, Renteria ME, et al. (2014): The ENIGMA Consortium: large-scale collaborative analyses of neuroimaging and genetic data. Brain imaging and behavior. 8:153-182.

43. Thompson PM, Andreassen OA, Arias-Vasquez A, Bearden CE, Boedhoe PS, Brouwer RM, et al. (2017): ENIGMA and the individual: Predicting factors that affect the brain in 35 countries worldwide. NeuroImage. 145:389-408.

44. van Erp TGM, Walton E, Hibar DP, Schmaal L, Jiang W, Glahn DC, et al. (2018): Cortical Brain Abnormalities in 4474 Individuals With Schizophrenia and 5098 Control Subjects via the Enhancing Neuro Imaging Genetics Through Meta Analysis (ENIGMA) Consortium. Biological psychiatry. 84:644-654. 45. van Erp TG, Hibar DP, Rasmussen JM, Glahn DC, Pearlson GD, Andreassen OA, et al. (2016): Subcortical brain volume abnormalities in 2028 individuals with schizophrenia and 2540 healthy controls via the ENIGMA consortium. Molecular psychiatry. 21:547-553.

46. Kong XZ, Postema MC, Guadalupe T, de Kovel C, Boedhoe PSW, Hoogman M, et al. (2020): Mapping brain asymmetry in health and disease through the ENIGMA consortium. Human brain mapping. -:1-15. 47. de Kovel CGF, Aftanas L, Aleman A, Alexander-Bloch AF, Baune BT, Brack I, et al. (2019): No Alterations of Brain Structural Asymmetry in Major Depressive Disorder: An ENIGMA Consortium Analysis. The American journal of psychiatry.appiajp201918101144.

48. Postema MC, van Rooij D, Anagnostou E, Arango C, Auzias G, Behrmann M, et al. (2019): Altered structural brain asymmetry in autism spectrum disorder in a study of 54 datasets. Nature communications. $10: 4958$ 
medRxiv preprint doi: https://doi.org/10.1101/2022.03.01.22271652; this version posted March 2, 2022. The copyright holder for this preprint

(which was not certified by peer review) is the author/funder, who has granted medRxiv a license to display the preprint in perpetuity.

It is made available under a CC-BY-NC 4.0 International license.

49. Kong XZ, Boedhoe PSW, Abe Y, Alonso P, Ameis SH, Arnold PD, et al. (2019): Mapping Cortical and Subcortical Asymmetry in Obsessive-Compulsive Disorder: Findings From the ENIGMA Consortium. Biological psychiatry.

50. Postema MC, Hoogman M, Ambrosino S, Asherson P, Banaschewski T, Bandeira CE, et al. (2021): Analysis of structural brain asymmetries in attention-deficit/hyperactivity disorder in 39 datasets. Journal of child psychology and psychiatry, and allied disciplines.

51. Gutman BA, van Erp TGM, Alpert K, Ching CRK, Isaev D, Ragothaman A, et al. (2021): A meta-analysis of deep brain structural shape and asymmetry abnormalities in 2,833 individuals with schizophrenia compared with 3,929 healthy volunteers via the ENIGMA Consortium. Human brain mapping.

52. Fischl B (2012): FreeSurfer. NeuroImage. 62:774-781.

53. Desikan RS, Ségonne F, Fischl B, Quinn BT, Dickerson BC, Blacker D, et al. (2006): An automated labeling system for subdividing the human cerebral cortex on MRI scans into gyral based regions of interest. NeuroImage. 31:968-980.

54. Fischl B, Salat DH, Busa E, Albert M, Dieterich M, Haselgrove C, et al. (2002): Whole brain segmentation: automated labeling of neuroanatomical structures in the human brain. Neuron. 33:341-355.

55. R Core Team (2021): R: A language and environment for statistical computing. Vienna, Austria: R Foundation for Statistical Computing.

56. Lo YC, Soong WT, Gau SS, Wu YY, Lai MC, Yeh FC, et al. (2011): The loss of asymmetry and reduced interhemispheric connectivity in adolescents with autism: a study using diffusion spectrum imaging tractography. Psychiatry research. 192:60-66.

57. Zhou D, Lebel C, Evans A, Beaulieu C (2013): Cortical thickness asymmetry from childhood to older adulthood. NeuroImage. 83:66-74.

58. Maingault S, Tzourio-Mazoyer N, Mazoyer B, Crivello F (2016): Regional correlations between cortical thickness and surface area asymmetries: A surface-based morphometry study of 250 adults. Neuropsychologia. 93:350-364.

59. Naimi B, Hamm NAS, Groen TA, Skidmore AK, Toxopeus AG (2014): Where is positional uncertainty a problem for species distribution modelling? Ecography. 37:191-203.

60. Nakagawa S, Cuthill IC (2007): Effect size, confidence interval and statistical significance: a practical guide for biologists. Biological reviews of the Cambridge Philosophical Society. 82:591-605.

61. Viechtbauer W (2010): Conducting Meta-Analyses in R with the metafor Package. Journal of Statistical Software. 36:48.

62. Benjamini Y, Hochberg Y (1995): Controlling the False Discovery Rate: A Practical and Powerful Approach to Multiple Testing. Journal of the Royal Statistical Society: Series B (Methodological). 57:289-300. 63. Harrer M, Cuijpers P, Furukawa T, Ebert DD (2019): dmetar: Companion R Package For The Guide 'Doing Meta-Analysis in R'. version 0.0.9000 ed.

64. Kay SR, Fiszbein A, Opler LA (1987): The positive and negative syndrome scale (PANSS) for schizophrenia. Schizophrenia bulletin. 13:261-276.

65. Andreasen NC (1984): The scale for the assessment of positive symptoms (SAPS). Iowa City: The University of Iowa.

66. Andreasen NC (1984): The scale for the assessment of negative symptoms (SANS). Iowa City, Iowa: The University of Iowa.

67. Kim S (2015): ppcor: An R Package for a Fast Calculation to Semi-partial Correlation Coefficients. Communications for statistical applications and methods. 22:665-674.

68. Radua J, Vieta E, Shinohara R, Kochunov P, Quidé Y, Green MJ, et al. (2020): Increased power by harmonizing structural MRI site differences with the ComBat batch adjustment method in ENIGMA. NeuroImage. 218:116956.

69. Labache L, Joliot M, Saracco J, Jobard G, Hesling I, Zago L, et al. (2019): A SENtence Supramodal Areas AtlaS (SENSAAS) based on multiple task-induced activation mapping and graph analysis of intrinsic connectivity in 144 healthy right-handers. Brain structure \& function. 224:859-882.

70. Sawilowsky SS (2009): New effect size rules of thumb. Journal of modern applied statistical methods. 8:26. 71. Francks C (2015): Exploring human brain lateralization with molecular genetics and genomics. Annals of the New York Academy of Sciences. 1359:1-13.

72. Vingerhoets G (2019): Phenotypes in hemispheric functional segregation? Perspectives and challenges. Physics of life reviews. 30:1-18.

73. Schmitz J, Fraenz C, Schlüter C, Friedrich P, Jung RE, Güntürkün O, et al. (2019): Hemispheric asymmetries in cortical gray matter microstructure identified by neurite orientation dispersion and density imaging. NeuroImage. 189:667-675.

74. Cui Y, Liu B, Song M, Lipnicki DM, Li J, Xie S, et al. (2018): Auditory verbal hallucinations are related to cortical thinning in the left middle temporal gyrus of patients with schizophrenia. Psychological medicine.

48:115-122. 
medRxiv preprint doi: https://doi.org/10.1101/2022.03.01.22271652; this version posted March 2, 2022. The copyright holder for this preprint

(which was not certified by peer review) is the author/funder, who has granted medRxiv a license to display the preprint in perpetuity.

It is made available under a CC-BY-NC 4.0 International license.

75. Sprooten E, Papmeyer M, Smyth AM, Vincenz D, Honold S, Conlon GA, et al. (2013): Cortical thickness in first-episode schizophrenia patients and individuals at high familial risk: a cross-sectional comparison.

Schizophrenia research. 151:259-264.

76. Hu M, Li J, Eyler L, Guo X, Wei Q, Tang J, et al. (2013): Decreased left middle temporal gyrus volume in antipsychotic drug-naive, first-episode schizophrenia patients and their healthy unaffected siblings.

Schizophrenia research. 144:37-42.

77. Cullen AE, De Brito SA, Gregory SL, Murray RM, Williams SC, Hodgins S, et al. (2013): Temporal lobe volume abnormalities precede the prodrome: a study of children presenting antecedents of schizophrenia.

Schizophrenia bulletin. 39:1318-1327.

78. Panizzon MS, Fennema-Notestine C, Eyler LT, Jernigan TL, Prom-Wormley E, Neale M, et al. (2009): Distinct genetic influences on cortical surface area and cortical thickness. Cerebral cortex (New York, NY : 1991). 19:2728-2735.

79. Grasby KL, Jahanshad N, Painter JN, Colodro-Conde L, Bralten J, Hibar DP, et al. (2020): The genetic architecture of the human cerebral cortex. Science (New York, NY). 367.

80. Tang W, Jbabdi S, Zhu Z, Cottaar M, Grisot G, Lehman JF, et al. (2019): A connectional hub in the rostral anterior cingulate cortex links areas of emotion and cognitive control. eLife. 8.

81. Bhojraj TS, Sweeney JA, Prasad KM, Eack SM, Francis AN, Miewald JM, et al. (2011): Gray matter loss in young relatives at risk for schizophrenia: relation with prodromal psychopathology. NeuroImage. 54 Suppl 1:S272-279.

82. He H, Luo C, Li N, Li Z, Duan M, Yao G, et al. (2021): Altered asymmetries of diffusion and volumetry in basal ganglia of schizophrenia. Brain imaging and behavior. 15:782-787.

83. Dougherty MK, Gu H, Bizzell J, Ramsey S, Gerig G, Perkins DO, et al. (2012): Differences in subcortical structures in young adolescents at familial risk for schizophrenia: a preliminary study. Psychiatry research. 204:68-74.

84. Smith KS, Tindell AJ, Aldridge JW, Berridge KC (2009): Ventral pallidum roles in reward and motivation. Behavioural brain research. 196:155-167.

85. Galderisi S, Mucci A, Buchanan RW, Arango C (2018): Negative symptoms of schizophrenia: new developments and unanswered research questions. The lancet Psychiatry. 5:664-677.

86. de Kovel CGF, Lisgo S, Karlebach G, Ju J, Cheng G, Fisher SE, et al. (2017): Left-Right Asymmetry of Maturation Rates in Human Embryonic Neural Development. Biological psychiatry. 82:204-212.

87. Hepper PG, Shahidullah S, White R (1991): Handedness in the human fetus. Neuropsychologia. 29:11071111.

88. Hering-Hanit R, Achiron R, Lipitz S, Achiron A (2001): Asymmetry of fetal cerebral hemispheres: in utero ultrasound study. Archives of disease in childhood Fetal and neonatal edition. 85:F194-196.

89. Hepper PG, Wells DL, Lynch C (2005): Prenatal thumb sucking is related to postnatal handedness. Neuropsychologia. 43:313-315.

90. Chiron C, Jambaque I, Nabbout R, Lounes R, Syrota A, Dulac O (1997): The right brain hemisphere is dominant in human infants. Brain : a journal of neurology. 120 ( Pt 6):1057-1065.

91. Joyce JJ, Dickson PI, Qi N, Noble JE, Raj JU, Baylen BG (2004): Normal right and left ventricular mass development during early infancy. The American journal of cardiology. 93:797-801.

92. Sha Z, Pepe A, Schijven D, Carrión-Castillo A, Roe JM, Westerhausen R, et al. (2021): Handedness and its genetic influences are associated with structural asymmetries of the cerebral cortex in 31,864 individuals. Proc Natl Acad Sci U S A. 118.

93. Roe JM, Vidal-Piñeiro D, Sørensen Ø, Brandmaier AM, Düzel S, Gonzalez HA, et al. (2021): Asymmetric thinning of the cerebral cortex across the adult lifespan is accelerated in Alzheimer's disease. Nature communications. 12:721.

94. Greve DN, Van der Haegen L, Cai Q, Stufflebeam S, Sabuncu MR, Fischl B, et al. (2013): A surface-based analysis of language lateralization and cortical asymmetry. Journal of cognitive neuroscience. 25:1477-1492. 95. Lv J, Di Biase M, Cash RFH, Cocchi L, Cropley VL, Klauser P, et al. (2020): Individual deviations from normative models of brain structure in a large cross-sectional schizophrenia cohort. Molecular psychiatry. 96. Liu Z, Palaniyappan L, Wu X, Zhang K, Du J, Zhao Q, et al. (2021): Resolving heterogeneity in schizophrenia through a novel systems approach to brain structure: individualized structural covariance network analysis. Molecular psychiatry. 